\title{
Senolytic-mediated elimination of head and neck tumor cells induced into senescence by cisplatin
}

\section{Fereshteh Ahmadinejad ${ }^{1 *}$, Tasia Bos ${ }^{2 *}$, Bin $\mathrm{Hu}^{3}$, Erin Britt ${ }^{2}$, Jennifer Koblinski ${ }^{3}$, Andrew}

\section{J. Souers 4 , Joel D. Leverson ${ }^{4}$, Anthony C. Faber², David A. Gewirtz ${ }^{5 \#}$, Hisashi Harada ${ }^{2 \#}$}

1: Department of Human and Molecular Genetics, School of Medicine, Massey Cancer Center, Virginia Commonwealth University, Richmond, Virginia

2: Philips Institute for Oral Health Research, School of Dentistry, Massey Cancer Center, Virginia Commonwealth University, Richmond, Virginia

3: Cancer Mouse Models Core, Massey Cancer Center, Virginia Commonwealth University, Richmond, Virginia

4: AbbVie, North Chicago, Illinois

5: Department of Pharmacology and Toxicology, School of Medicine, Massey Cancer Center, Virginia Commonwealth University, Richmond, Virginia

*Equally contributed to this work 
Running title: Recovery and elimination of senescent tumor cells

Keywords: senescence, chemotherapy, senolytic, head and neck cancer, ABT-263

\#To whom correspondence should be addressed at:

Massey Cancer Center, Virginia Commonwealth University

401 College St., Richmond, VA 23298

Phone: 804-828-9523, 804-628-0064

Email: david.gewirtz@vcuhealth.org, hharada@vcu.edu

The number of text pages: 23

The number of tables: 0

The number of figures: 7

The number of references: 86

The number of words in the Abstract: 231

Introduction: 711

Discussion: 1445 


\section{Abstract:}

Therapeutic outcomes achieved in head and neck squamous cell carcinoma (HNSCC) patients by concurrent cisplatin-based chemoradiotherapy initially reflect both tumor regression and tumor stasis. However, local, and distant metastasis and disease relapse are common in HNSCC patients. In the current work, we demonstrate that cisplatin treatment induces senescence in both p53 wildtype HN30 and p53 mutant HN12 head and neck cancer models. We also show that tumor cells can escape from senescence both in vitro and in vivo. We further establish the effectiveness of the senolytic, ABT-263 (Navitoclax), in elimination of senescent tumor cells after cisplatin treatment. Navitoclax increased apoptosis by 3.3 -fold $(\mathrm{p} \leq 0.05)$ at Day 7 compared to monotherapy by cisplatin. Additionally, we show that ABT-263 interferes with the interaction between BCL- $\mathrm{X}_{\mathrm{L}}$ and BAX, anti- and pro-apoptotic proteins, respectively, followed by BAX activation, suggesting that ABT-263 induced apoptotic cell death is mediated through BAX. Our in vivo studies also confirm senescence induction in tumor cells by cisplatin, and the promotion of apoptosis coupled with a significant delay of tumor growth after sequential treatment with ABT-263. Sequential treatment with cisplatin followed by ABT-263 extended the humane endpoint to 130 days compared to cisplatin alone, where mouse survived $\sim 75$ days. These results support the premise that senolytic agents could be utilized to eliminate residual senescent tumor cells after chemotherapy and thereby potentially delay disease recurrence in head and neck cancer patients. 


\author{
Abbreviations: \\ Cis Cisplatin \\ HNSCC Head and Neck Squamous Cell Carcinoma \\ SASP Senescence-associated secretory phenotype \\ SA- $\beta$-Gal Senescence-associated beta galactosidase \\ BCL-2 B-cell lymphoma-2 \\ BCL-X $\quad$ B-cell lymphoma-x large \\ BH3 BCL-2 homology 3 \\ 4NQO 4-nitroquinoline 1-oxide \\ FACS fluorescence activated cell sorting
}

Significance Statement: Disease recurrence is the most common cause of death in head and neck cancer patients. BCL-XL inhibitors such as ABT-263 (Navitoclax) have the capacity to be used in combination with cisplatin in head and neck cancer patients to eliminate senescent cells and possibly prevent disease relapse. 


\section{Introduction}

Head and neck cancer is the sixth most common type of malignancy worldwide, with head and neck squamous cell carcinomas (HNSCCs) accounting for $>90 \%$ of cases. HNSCC incidence largely correlates with tobacco and alcohol usage and is often diagnosed in advanced stages (Leemans et al., 2011). There is also a rapidly increasing incidence of a human papillomavirusrelated (HPV+) subtype of HNSCC, which arises in a younger patient demographic that includes many never-smokers (Donà et al., 2020).

Head and neck cancer is generally treated with a combination of surgery, radiation and chemotherapy, with cisplatin being a primary therapeutic modality (Cramer et al., 2019; Chow, 2020). Despite recent advances in cancer therapeutic approaches, $40 \%$ and $20 \%$ of patients with HPV-negative HNSCC experience locoregional and distant failure, respectively, after cisplatinbased chemoradiotherapy. While head and neck cancer is generally responsive to initial therapy, the disease almost invariably recurs, often becoming refractive to further therapy (Gibson et al., 2005; Argiris et al., 2008). An accumulating body of evidence has shown that cancer relapse often occurs after both conventional and advanced therapeutic approaches, where the therapy results in an accumulation of non-proliferative residual cancer cells (Goss and Chambers, 2010; Kareva, 2016). The cross talk between these tumor cells and their microenvironment can result in escape from the growth-arrested state via recovery of the cellular proliferative capacity, leading to disease recurrence (Sosa et al., 2014; Yeh and Ramaswamy, 2015).

The mechanism(s) whereby the residual cells maintain their long-term survival is poorly understood, but a significant number of recent studies have shown that transient senescence, the tumor cells' primary response to subtoxic doses of chemotherapy and/or radiation, can potentially contribute to cancer recurrence (Demaria et al., 2017; Duy et al., 2021). Senescence in cancer was 
first described as the limited proliferative capacity of tumor cells in response to activated oncogenes, oxidative stress, specific cytokines and chemokines, and DNA damage induced by chemicals such as chemotherapeutic agents (therapy-induced senescence) (Ewald et al., 2010). Senescence was originally considered to represent an irreversible form of growth arrest; however, studies in various cancer models including lung, prostate, and breast (Elmore, 2005; Roberson et al., 2005; Wang et al., 2013; Chitikova et al., 2014; Saleh et al., 2019) have shown that while therapy-induced senescence in cancer cells is durable, it does not actually represent a permanent form of growth arrest. Consequently, the senescence phenotype is not necessarily a favorable outcome of cancer therapy. In addition to cell cycle arrest, senescence is characterized by pronounced alterations in cells morphology, increased lysosomal biogenesis with $\beta$-galactosidase expression, facultative heterochromatin condensation and foci formation $\mathrm{H} 3 \mathrm{~K} 9 \mathrm{Me} 3$ (SAHF), and secretion of various inflammatory cytokines and chemokines such as IL-6, IL-8, IL-1 $\beta$, and MMP3, reflecting the senescence-associated secretory phenotype (SASP) (Sharpless and Sherr, 2015; Hernandez-Segura et al., 2018).

Senolytics are a relatively new class of drugs that have been shown to selectively induce cell death in senescent cells (Baker et al., 2011; Saleh, Carpenter, et al., 2020). One of the extensively characterized and effective senolytics is a BH3 mimetic, specifically the BCL-2 and BCL-XL inhibitor known as ABT-263 (Navitoclax) (Saleh, Carpenter, et al., 2020). Navitoclax has been shown to have high affinity towards the hydrophobic pocket of anti-apoptotic proteins such as BCL-2 and BCL-X (Chen et al., 2011). Upon binding, pro-apoptotic proteins such as BAX/BAK are released from these anti-apoptotic proteins, resulting in the activation of proapoptotic BAX/BAK to initiate apoptosis by releasing cytochrome $\mathrm{c}$ from mitochondria to the cytosol followed by caspase activation (Mérino et al., 2012). Studies have shown that anti- 
apoptotic BCL-2 family proteins are often overexpressed in cancer cells after chemotherapy or radiation, which is thought to be a central mechanism by which cancer cells survive beyond firstline therapies and, ultimately leading to metastasis and cancer recurrence (Raffo et al., 1995). Navitoclax has demonstrated activities in investigational clinical trials both as a single agent and in combination with chemotherapy or radiation in different cancer types (Rudin et al., 2012; Puglisi et al., 2021).

The current studies demonstrated transient senescence induction by cisplatin in human and murine head and neck cancer cell lines and in head and neck cancer mouse models. Furthermore, escape from senescence was observed in experimental models of head and neck cancer whereas navitoclax was shown to have senolytic activity both in culture and in tumor bearing animals. Mechanistic studies identified BCL- $\mathrm{X}_{\mathrm{L}}$ as a primary target of navitoclax for the killing of senescent head and neck cancer cells. BCL-XL was induced after cisplatin treatment, whereas navitoclax administration released BAX from the BCL-XL/BAX complex to induce apoptosis specifically in senescent cells. Finally, sequential treatment with cisplatin followed by navitoclax significantly delayed tumor growth and prolonged survival in the mouse model of head and neck cancer. 


\section{Materials and methods}

\section{Cell lines and drug treatments}

Investigations were carried out on two HPV-negative human HNSCC cell lines, HN30 (wild-type p53) and HN12(truncated non-functional p53), which were provided by Dr. Andrew Yeudall (Augusta University). Cells were cultured in DMEM (Thermo Fisher, 10569010) supplemented with $10 \%$ (v/v) fetal bovine serum (Gemini, 26140), $100 \mathrm{U} / \mathrm{ml}$ penicillin G sodium and $100 \mu \mathrm{g} / \mathrm{ml}$ streptomycin sulfate (Thermo Fisher, 15140148) at $37^{\circ} \mathrm{C}$ and $5 \% \mathrm{CO}_{2} . \mathrm{HN} 30 \mathrm{BAX}$ and BAK knock-down cell lines were established by viral particles generated by HEK293T cells after co-transfection with appropriate shRNA plasmids, psPAX2 (addgene, 12260), and pMD2.G (Addgene, 12259) with EndoFectin-Lenti (GeneCopoeia, EF013). Next, viral supernatants were collected and used for HN30 cells transduction. Finally, transduced cells were selected by $2 \mu \mathrm{g} / \mathrm{ml}$ puromycin in several passages for a pure knocked-down population. Cisplatin (Sigma-Aldrich, 15663-27-1, $\geq 98 \%$ (HPLC) was dissolved in PBS, and ABT-263 (AbbVie Inc), ABT-199 (APExBio, A8194, 98.07\% HPLC), and A-1155463 (APExBio, B6163, 98.78\% HPLC) were dissolved in DMSO and administered in the dark at the desired concentrations. Drugs are stable after preparation and were kept at $-20^{\circ} \mathrm{C}$ in the dark.

\section{Cell viability and clonogenic survival assays}

Cell viability was determined by monitoring the number of viable cells over time using trypan blue dye exclusion staining before, during, and after drug treatment. Cells were treated with $5 \mu \mathrm{M}$ cisplatin for 24 hours and were collected by trypsinization at specific time points, and stained with $0.4 \%$ trypan blue (Sigma, T8154) and counted using hemocytometer under light microscopy. For clonogenic survival assays, cells were seeded at a low density at $5 \times 10^{3} / 10 \mathrm{~cm}$ dish or $1,000 / 6-$ well plates, then treated $2 \mu \mathrm{M}$ ABT-263, ABT-199, A-1155463 or vehicle for 24 hours. Colony 
formation was monitored overtime, and at the experiment end point (at Day 14, when the vehicletreated condition formed distinct colonies with more than 50 cells), colonies were fixed with $100 \%$ methanol, air-dried, stained with $0.05 \%$ crystal violet and counted using a colony counter (COLOCOUNT Discovery Technology Intl).

\section{SA-ß-galactosidase Staining/Enrichment}

Histochemical staining of SA- $\beta$-gal was performed as previously described (Dimri et al., 1995; Debacq-Chainiaux et al., 2009). Images were taken by a bright field inverted microscope (Olympus inverted microscope IX70, 20x objective, Q-Color3 ${ }^{\mathrm{TM}}$ Camera; Olympus, Tokyo, Japan). The $\mathrm{C}_{12} \mathrm{FDG}$ flow cytometry was performed using the protocol described by DebacqChainiaux et al (Debacq-Chainiaux et al., 2009). At the specific time points, cells were collected, washed with PBS, and analyzed by flow cytometry (using BD FACSCanto II and BD FACSDiva software at the Virginia Commonwealth University Flow Cytometry Core Facility). Similarly, for immunofluorescent staining of $\mathrm{C}_{12} \mathrm{FDG}$, cells were exposed to $100 \mathrm{nM}$ of bafilomycin $\mathrm{A} 1$ (Sigma Aldrich, B1793, >90\% HPLC) for one hour, and after increasing the lysosomal PH, cells were exposed to $100 \mu \mathrm{M} \mathrm{C}{ }_{12} \mathrm{FDG}$ (Thermo Fisher, D2893) for 2 hours. After washing with PBS, nuclei were stained with Hoechst 33342 (Thermo Fisher, 33342) for 20 minutes in complete media. Images were taken using the Olympus inverted microscope. To enrich the senescent population, cells were seeded at high density for $1-2 \times 10^{6} / 150 \mathrm{~mm}$ dish and cultured overnight. The next day, cells were treated with cisplatin, and at the indicated time points, they underwent $\mathrm{C}_{12} \mathrm{FDG}$ staining as described above. Finally, cells were sorted by FACS. All the above experiments were performed at Day 5 after treatment with $5 \mu \mathrm{M}$ cisplatin for 24 hours.

\section{Total cell lysates, subcellular fractionation, and Western blotting}


Molecular Pharmacology Fast Forward. Published on December 14, 2021 as DOI: 10.1124/molpharm.121.000354

This article has not been copyedited and formatted. The final version may differ from this version.

Total cell lysates were prepared using the CHAPS buffer [20 mM Tris ( $\mathrm{pH} 7.4), 137 \mathrm{mM}$ $\mathrm{NaCl}, 1 \mathrm{mM}$ dithiothreitol (DTT), 1\% CHAPS (3-[(3-Cholamidopropyl) dimethylammonio] 1propanesulfonate)]. The mitochondria fraction was prepared with Qproteome Mitochondria Isolation Kit (Qiagen, 37612) according to the manufacture's protocol. Western blotting was performed as described (Sharma et al., 2014). Antibodies used in 1:1000 dilution: cleaved PARP (Cell Signaling, 5625), cleaved caspase 3 (Cell Signaling, 9664,), GAPDH (Cell Signaling, 5174), BCL-2 (Sigma, B3170), BCL-XL (Cell Signaling, 2764), BAX (Cell Signaling, 2772), BAK (Cell Signaling, 12105), p53 (Santa Cruz, 23959), p21 (Cell Signaling, 2947), COX-IV (Cell Signaling, 4850).

\section{Co-immunoprecipitation}

BCL-X $($ Cell Signaling, 2764) or BAX (Santa Cruz, 23959) primary antibodies (1:100 dilution) were added to equal amounts of total lysates extracted from treated and non-treated cells. After an overnight incubation at $4^{\circ} \mathrm{C}$, Protein A/G beads (Thermo Fisher, 53132) were added for 1 hour incubation at $4^{\circ} \mathrm{C}$ to precipitate the protein-antibody complexes. Samples were centrifuged, washed, and resuspended in 50/50 CHAPS buffer and 2X SDS-loading buffer. After boiling the samples for 5 mins, they were subjected to SDS-PAGE followed by Western blotting as described above.

\section{Cell cycle, Annexin-V/PI staining, and $\gamma-H 2 A X$ analysis}

Cell cycle analysis was performed based on propidium iodide staining (Saleh et al. 2019), and apoptosis quantification was done using AnnexinV-FITC apoptosis detection kit (556547, BD Biosciences, NJ, USA). Cells were seeded at the density of $4 \times 10^{4}$ cells per milliliter, treated with $5 \mu \mathrm{M}$ cisplatin for 24 hours, and harvested at the indicated time points. After washing the samples with PBS, cells were resuspended in $100 \mu \mathrm{l}$ of 1x Binding Buffer and incubated for 15 min in the 
dark at RT. Up to $500 \mu \mathrm{l}$ of extra binding buffer was added to the final suspension and then the samples were analyzed by flow cytometry. Cell cycle analysis was performed at Day 5 after treatment with cisplatin, and apoptosis was assessed at Day 7. For $\gamma$-H2AX analysis, cells were seeded at a density of $4 \times 10^{4}$ cells per milliliter, treated with $5 \mu \mathrm{M}$ cisplatin or vehicle for 24 hours. At Day 5, $2 \mu \mathrm{M}$ ABT-263 was added to the combination conditions for 48 hours and $\gamma-\mathrm{H} 2 \mathrm{AX}$ induction was monitored by flow cytometry at Day 7. Cells were harvested, fixed with $3.7 \%$ formaldehyde and permeabilized with cold methanol. After washing the pellets, cells were incubated with 1:250 dilution of $\gamma$-H2AX antibody conjugated to FITC (anti-H2AX (pS139), BD Biosciences, Cat. No. 560443) for 30 minutes.

\section{Live-cell imaging}

HN30 cells were plated $\left(5 \times 10^{5}\right.$ cells per milliliter $)$ in 6 -well plates and incubated overnight. After treatment with $5 \mu \mathrm{M}$ cisplatin or vehicle for 24 hours, the plates were immediately placed on a CytoSMART digital microscopy system inside a humidified $\mathrm{CO}_{2}$ incubator at $37^{\circ} \mathrm{C}$. Live time lapse images were taken every 15 min for 48 hours on Day 5 (growth arrested and control cells, respectively) and Day 10 (cells escaping from senescence and recovering their proliferative capacity).

\section{$q R T-P C R$}

Cells were plated $\left(5 \times 10^{5}\right.$ cells per milliliter $)$ and treated with $5 \mu \mathrm{M}$ cisplatin for 24 hours. At Day 5, cells were harvested, and total RNA was extracted using RNeasy kit (QIAGEN, 74004) following the manufacturer's instructions. cDNA was synthesized using iScript cDNA Synthesis Kit (BioRad, 4106228) based on the protocol that manufacture provided. cDNAs from different samples were amplified in technical triplicates using iTaq Universal SYBR® Green Supermix (BioRad, 10000068167) in QuantStudio ${ }^{\text {TM }} 3$ Real-Time PCR System (Thermo Fisher). QuantiTect 
primers were purchased from Qiagen: CXCL8: QT0000322; IL-6: QT00083720; IL-1 $\beta$ : QT00021385; MMP3: QT00060025; GAPDH: QT00079247. Relative mRNA expression was determined using the $\Delta \Delta \mathrm{Ct}$ method.

\section{In-vivo experiments}

All animal studies were conducted in accordance with Virginia Commonwealth University IACUC guidelines. We first established the mouse oral squamous cell carcinoma (OSCC) cell line, 602, derived from the 4-nitroquinoline-1 oxide (4NQO)-developed tumor on the tongue. Female C57BL/6 mice (5 weeks of age; Envigo) were treated with $50 \mu \mathrm{g} / \mathrm{ml}$ 4NQO-containing water for 16 weeks. Then the drinking water was reverted to regular water until Week 22. When a single lesion on the tongue became $\sim 50 \mathrm{~mm}^{3}$, a tumor was removed and digested, and cells were isolated to establish a cell line. To establish tumors, 1 x $10^{6}$ of 602 OSCC cells were suspended in 50/50 PBS-Cultrex basement membrane matrix (Cultrex, 3632-005-02) and subcutaneously inoculated into the rear flanks of C57BL/6 female mice (Day 0). When tumor size approached $\sim 100 \mathrm{~mm}^{3}$, mice were randomized in five groups (Day 13, $\mathrm{N}=6 /$ group) and treated with cisplatin $(5 \mathrm{mg} / \mathrm{kg}$ ) by intraperitoneal injections at Day 13, 16, 20 and 23, then with ABT-263 (80 mg/kg) by oral gavage daily at Day 27-31 and Day 34-38. The second round of treatments was performed with cisplatin at Day 41, 44 and 48, followed with ABT-263 at Day 55-59 and Day 62-66. Tumor volumes were taken by manual caliper measurements.

\section{Immunohistochemistry}

For cleaved caspase-3 (Cell Signaling, 9664) and $\gamma$-H2AX (Cell Signaling, 9718), tumors were fixed in $10 \%$ formalin phosphate buffer and performed on BOND RX Fully Automated Research Stainer. Slides were stained overnight at $4^{\circ} \mathrm{C}$ with cleaved caspase-3 (1:500) or $\gamma-\mathrm{H} 2 \mathrm{AX}$ (1:400) primary antibodies then for $8 \mathrm{~min}$ at room temperature with the secondary antibody 
included in the BOND Polymer Refine Detection kit (Leica, DS9800). Slides were mounted with Dako CoverStainer (Agilent). Images were taken on Vectra Polaris Automated Quantitative Pathology Imaging System (Akoya Biosciences) at 20X at the VCU Cancer Mouse Models Core (CMMC). For X-Gal staining, tumors were frozen into OCT molds and cut into 10-micron sections by the VCU Tissue and Data Acquisition and Analysis Core (TDACC).

\section{Blood analysis and platelet/neutrophil counts:}

Mice treated with vehicle, cisplatin, ABT-263, or a combination of cisplatin and ABT-263 were subjected to Complete Blood Count (CBC) analysis at the indicated time points (Figure 6E). Blood samples $(\sim 0.2 \mathrm{ml})$ were collected by facial vein using EDTA coated syringes and immediately analyzed by hematology analyzer Hemavet 950FS (Drew Scientific, Miami Lakes, FL, USA) at the VCU CMMC.

\section{Statistical Analysis}

Unless otherwise indicated, all quantitative data is shown as mean \pm SD from at least three independent experiments(biological replicates), all of which were conducted in triplicates or duplicates(technical replicates). GraphPad Prism 6.0 software was used for statistical analysis. All data was analyzed using either a one- or two-way ANOVA, as appropriate, with Tukey or Sidak post hoc, with the exception of cell cycle, $\mathrm{C}_{12} \mathrm{FDG}$ data, and platelet counts which were analyzed with unpaired, student's t-tests. 


\section{Results}

\section{Cisplatin induces growth arrest and senescence in head and neck cancer cells}

Pharmacokinetic studies have indicated that the highest plasma concentration of cisplatin achieved in patients is $12 \mu \mathrm{M}$ at 5 minutes after injection, while the plasma concentration decreases to $5.9 \mu \mathrm{M}$ after 2 hours. Up to $90 \%$ of total cisplatin is excreted (depending on the patient's renal function) in 24 hours. Consequently, initial experiments to investigate the cellular response to cisplatin in head and neck cancer cells involved exposure to clinically relevant concentrations of cisplatin $(2,5$ and $10 \mu \mathrm{M})$ for 24 hours (Farris et al., 1988; Urien and Lokiec, 2004; Ang et al., 2014). As expected, cisplatin induced a temporary growth arrest after 24 hours of treatment in both HN30 (p53 wild-type) and HN12 (p53-null) head and neck cancer cell lines. As we have reported in other tumor cell models (Saleh et al., 2019; Saleh, Carpenter, et al., 2020), the cells ultimately escaped and recovered their proliferative capacity (Figure 1A). Cell cycle analyses confirmed that both cell lines arrested primarily at the G0/G1 phase (Figure 1B).

The antitumor activity of cisplatin is generally ascribed to the induction of DNA singleand double-strand breaks subsequent to the cross-linking of DNA (Jeon et al., 2008; Basu and Krishnamurthy, 2010; Rezaee et al., 2013). Consistent with the fact that senescence has been suggested to be the primary response of tumor cells to chemotherapeutic agents and cellular stress conditions (Triana-Martínez et al., 2020), we confirmed that cisplatin promotes senescence in our experimental models. This determination was based on a number of characteristics such as morphological changes, qualitative and quantitative measurement of SA- $\beta$-gal activity using Xgal staining (Figures 1C, Upper portion) and fluorescence-based labeling with $\mathrm{C}_{12} \mathrm{FDG}$ (Figures 1C, right panels, and S1), and upregulation of the tumor suppressor p53 and the cyclin-dependent kinase inhibitor p21 (Figure 1D). Additional senescence markers, specifically heterochromatic 
foci (H3K9Me3) formation (Figure 1C, lower panels) and increased expression of SenescenceAssociated Secretory Phenotype (SASP) components such as $I L-6, I L-8$, and $I L-1 \beta$, (Figure 1E) further confirmed that cisplatin treatment can promote senescence in HNSCC cells regardless of the $p 53$ status.

Proliferative recovery in cisplatin-treated HNSCC cells is associated with a decline in senescence markers

Despite the long-held paradigm that therapy-induced senescence (TIS) is an irreversible and permanent form of growth arrest, which would be consistent with a favorable therapeutic outcome of senescence induction (Shay and Roninson, 2004), our previous studies along with rigorous experiments by other investigators have firmly established that at least a subpopulation of cells can and will evade the senescent arrest and re-emerge with self-renewal capacity (Elmore, 2005; Roberson et al., 2005; Puig et al., 2008; Wang et al., 2013; Chitikova et al., 2014; Saleh, Carpenter, et al., 2020). To interrogate whether this is also the case for head and neck cancer cells induced into senescence by cisplatin, we utilized multiple approaches to investigate the capacity for proliferative recovery from senescence in our experimental models. Live-cell imaging microscopy was utilized to monitor proliferative recovery from cisplatin-induced senescent HN30 cells (Videos S1A, B, and C). A comparison of the morphologic characteristics of cells at different time points established that the emerging population at Day 11 in Video S1C was indeed derived from the senescent population. Further confirmation of the involvement of senescence in recovery was based on the observation that proliferative recovery in our models is associated with diminution of the senescence markers (Figure 2). Specifically, SA- $\beta$-gal activity showed a significant reduction after the cells recovered their proliferative capacity (Figure 2A). Similarly, the decline in additional senescence markers such as components of the senescence-associated 
secretory phenotype (SASP) (Figure 2B), further indicates that the cisplatin-induced senescentlike state is not sustained.

It is possible that the recovered population originated from a subclone that was resistant to the primary effects of cisplatin de novo rather than via escape from chemotherapy-induced senescence (Beausejour, 2003; Dirac and Bernards, 2003). To confirm that cells can and do recover from chemotherapy-induced senescence, cisplatin-induced senescent cells were labeled with the fluorescent substrate of SA- $\beta$-gal, $\mathrm{C}_{12} \mathrm{FDG}$, and enriched for the highest $\sim 30 \%$ of the $\mathrm{C}_{12} \mathrm{FDG}$ positive (SA- $\beta$-gal-positive) and morphologically enlarged population using fluorescenceactivated cell sorting (FACS). This protocol ensures a highly specific and selective purification of senescent population from a heterogeneous mixture of tumor cells after treatment. The highly $\mathrm{C}_{12} \mathrm{FDG}$-positive population was then re-plated and monitored for senescence markers such as proliferative arrest, and SA- $\beta$-gal activity. As shown in Figures $2 \mathrm{C}$ and 2D, the sorted population recovered proliferative capacity after 16 days accompanied by the suppression of SA- $\beta$-gal activity.

\section{ABT-263 selectively eliminates senescent tumor cells in vitro}

The proliferative recovery in tumor cells re-emerging from a therapy-induced senescent population has been shown to contribute not only to recurrence of a more aggressive form of the disease, but also to acquired resistance to chemotherapy or radiation (Rebbaa, 2005; Yang et al., 2017). Consequently, in an effort to eliminate the cisplatin-induced senescent population, cisplatin-treated HN30 and HN12 cells were exposed to a single dose of ABT-263, an agent that has demonstrated senolytic properties (Sharma et al., 2014; Lafontaine et al., 2021) for 24-hours. A significant decrease in the number of viable cells (Figure 3A) strongly suggests that ABT-263 selectively eliminates cisplatin-treated senescent cells, while showing minimal effects on untreated 
cells. Clonogenic survival assays using increasing concentrations of ABT-263 on non-treated tumor cells confirmed that ABT-263 alone, even at higher concentrations, was ineffective in perturbing colony formation for non-senescent tumor cells (Figure S2A). This result was recapitulated with selective inhibitors of BCL-2 (ABT-199) and BCL-XL (A-1155463) (Figures S2B and S2C). In addition, ABT-263 treatment resulted in a significant decrease in the SA- $\beta$-gal positive (senescent) population (Figure S2D), further confirming the selective activity of ABT263 for the senescent population. As we have reported previously in models of non-small cell lung cancer and breast cancer (Alotaibi et al., 2016; Saleh et al., 2019), ABT-263 effectiveness diminishes over time as the treated cells escape senescence and recover their proliferative capacity (Figure S2E, lower panel) in marked contrast to the effectiveness of ABT-263 after a second dose of cisplatin (Figure S2E, upper panel). This observation reaffirms the selectivity of ABT-263 for a senescent cell population.

Consistent with previously published studies on ABT-263 as an apoptosis inducing agent (Tse et al., 2008), there was a significant increase in Annexin-V/PI staining and the apoptosis marker, cleaved-caspase-3, in the combinatorial treatment group (cisplatin followed by ABT-263) compared to cisplatin or ABT-263 alone (Figures 3B and 3C). Taken together, these observations strongly confirm that ABT-263 acts as a selective senolytic in vitro by significantly decreasing the number of cisplatin-induced senescent cells.

The $B C L-X_{L} / B A X$ axis is the primary target for cell death induced by ABT-263 in cisplatininduced senescent HNSCC cells

ABT-263 is known to specifically inhibit the function of the anti-apoptotic BCL-2 and BCL-X proteins to induce apoptotic cell death (Tse et al., 2008). In order to delineate the specificity of the inhibitory activity in head and neck cancer, we treated cisplatin-induced 
senescent HN30 cells with a BCL-2 specific inhibitor, ABT-199 and a BCL-XL specific inhibitor, A-1155463. These agents do not have an effect on non-senescent HN30 cells (Figures S3A, S3B, S2A, S2B, and S2C). However, A-1155463, but not ABT-199, eliminated senescent cells, suggesting that BCL- $\mathrm{X}_{\mathrm{L}}$ is the primary target in senescent HNSCC cells (Figures 4A, and S3A). We further confirmed that ABT-263 and A-1155463-mediated cell death was occurring primarily via apoptosis using Annexin-V staining (Figure 4C). Similar specificity to BCL-XL was also observed in p53-null HN12 cells (Figure 4B, 4D, and S3B) These results strongly suggest that BCL- $\mathrm{X}_{\mathrm{L}}$ is the primary target of ABT-263-induced senolytic cell death.

In order to further support that the senolytic activity of ABT-263 in head and neck cancer cells was driven by inhibition of BCL-X $\mathrm{X}_{\mathrm{L}}$, we next determined the expression of major BCL-2 family proteins in cisplatin-induced senescence HN30 cells. The level of the anti-apoptotic protein, BCL-X $\mathrm{X}_{\mathrm{L}}$ gradually increased following cisplatin treatment (Figure 5A). Consistently, these increases were also observed in the HN12 cells (Figure 5B). Changes of other BCL-2 family proteins were inconsistent (Figures 5A and 5B).

ABT-263 inhibits the interaction of $\mathrm{BCL}-\mathrm{X}_{\mathrm{L}}$ with $\mathrm{BAX} / \mathrm{BAK}$, thereby inducing apoptosis(Saleh, Carpenter, et al., 2020). To elucidate the involvement of these executioner proapoptotic proteins following ABT-263 treatment, we established stable HN30 cells with shRNA for BAX (shBAX), BAK (shBAK) or scrambled-control (shC) (Figure 5C). Although these cell lines undergo similar induction of senescence following exposure to cisplatin (Figure 5D, bottom), cisplatin-treated shBAX-expressing cells, but not shBAK expressing cells, failed to undergo cell death following exposure to ABT-263 (Figure 5D, top), indicating that BAX is essential to ABT-263-induced senolysis. 
The above results prompted us to investigate the subcellular localization of BAX and BCL$\mathrm{X}_{\mathrm{L}}$, their interaction, and BAX conformational change/activation. The mitochondria-enriched lysates revealed the accumulation of BAX in cisplatin-induced senescent and further in ABT-263treated HN30 cells (Figure 5E). In contrast, the amounts of BCL-X $\mathrm{X}_{\mathrm{L}}$ and BAK at the mitochondria were only modestly perturbed (Figure 5E). We then investigated the BCL-X $/$ BAX interaction by co-immunoprecipitation experiments. When BCL-XL was immunoprecipitated, BAX was present in both the control and cisplatin treatment groups. However, when ABT-263 was introduced, the BCL-X $\mathrm{X}_{\mathrm{L}} \mathrm{BAX}$ interaction was significantly decreased (Figure 5F), suggesting that ABT-263 inhibits the BCL-X $\mathrm{X} / \mathrm{BAX}$ interaction and releases BAX from the complex. This result indicated that BAX became activated to allow apoptosis to occur.

\section{ABT-263 selectively eliminates cisplatin-induced mouse oral squamous cell carcinoma cells in} vitro and in vivo

In order to test the senolytic activity of ABT-263 in vivo, we first established the mouse oral squamous cell carcinoma (OSCC) cell line (602) derived from the 4-nitroquinoline-1 oxide (4NQO)-developed tumor on the tongue (see Materials and Methods). A crystal violet and senescence associated- $\beta$-galactosidase (SA- $\beta$-gal) stain revealed that cisplatin induced 602 cells into senescence and sensitized the cells to ABT-263 (Figure 6A). We then evaluated senolytic activity of ABT-263 in a syngeneic mouse model. Cisplatin treatment resulted in brief tumor stasis compared to the control and ABT-263 monotherapy (Figure 6B). Sequential cisplatin and ABT263 treatment resulted in a distinct therapeutic benefit characterized by delayed tumor recurrence and longer survival (Figure 6B and 6C). Furthermore, two rounds of cisplatin followed by ABT263 treatment (combination B) outperformed all groups, including the single round of cisplatin 
followed by ABT-263 (combination A), in terms of delayed tumor recurrence and improved animal survival. Animal experiment diagram is presented in Figure $\mathbf{S 4}$.

We further extracted and analyzed the 602 tumors to evaluate markers of senescence and the senolytic activity of ABT-263. Cisplatin-induced senescence in tumors in vivo was clearly detected as X-gal staining with increased SA- $\beta$-gal activity, which was then decreased upon ABT263 treatment (Figure 6D, left panels). Cisplatin also induces DNA single- or double-strand breaks (DSBs). The phosphorylated form of histone H2AX ( $\gamma-\mathrm{H} 2 \mathrm{AX})$ marks sites of DNA DSB repair. Compared to the control, $\gamma-\mathrm{H} 2 \mathrm{AX}$ was strongly stained in tumors exposed to cisplatin (Figure 6D, middle panels). However, ABT-263 did not appear to alter the levels of $\gamma$-H2AX either alone or in combination with cisplatin, both in the tumor bearing animal experiments (Figure 6D), and in the cell culture studies (Figure S5). Extensive cleavage of caspase-3 (c-casp3), indicative of apoptosis, was evident in tumors treated with cisplatin followed by ABT-263 (Figure 6D, right panels). These results suggest that the benefit of sequential treatment is a result of apoptosis caused by ABT-263 in cisplatin-induced senescent tumors.

Based on the previous preclinical data in animal models (Shoemaker et al., 2006), ABT263 treatment results in rapid and concentration dependent thrombocytopenia that resolves after drug cessation (Oltersdorf et al., 2005; Roberts et al., 2009). Here, we evaluated the safety of ABT263 is our animal model by analyzing Complete Blood Counts (CBC), particularly by focusing on the dynamic of circulating platelets and neutrophils (Figures 7 and S6). The number of circulating platelets and neutrophils in the different groups of mice show that ABT-263 treatment alone or in combination with cisplatin does not result in thrombocytopenia or neutropenia in our experimental model system. 


\section{Discussion}

Locoregional and distant recurrence are the most common cause of death in HNSCC patients, and it has been suggested that the morbidity and mortality is mediated by the progression from residual tumor cells that survive from the assault of chemotherapy or radiotherapy (Lambrecht et al., 2009). A similar contribution to recurrence from residual tumor cells is also observed in breast, prostate, and lung cancer; more specifically, whereas the initial therapies result in both tumor regression and stasis, a residual cell population can proliferate at secondary local or distant sites with equal or more aggressiveness (Morgan et al., 2009; Walens et al., 2019; Wu et al., 2020). This residual and dormant cell population could potentially be linked to senescent and quiescent tumor cells as well as cancer stem cells (Kim et al., 2012; Wang et al., 2017; Phi et al., 2018).

Despite the fact that therapy-induced senescence has been investigated for decades, the contribution of senescent tumor cells to disease recurrence is still obscure (Pérez-Mancera $e t$ al., 2014). The senescence phenotype was initially considered as a favorable outcome of cancer therapy, as it likely represents a primary response to chemotherapy or radiation and cells in this state manifest characteristics such as prolonged growth arrest, which may lead to tumor regression (Nardella et al., 2011). However, as senescent cells are metabolically active and resistant to apoptosis(Seluanov et al., 2001; Wiley et al., 2017), it is anticipated that the considerable heterogeneity of senescent tumor populations would allow for proliferative recovery of some tumor subpopulations from the state of growth arrest (Hernandez-Segura et al., 2017; Wiley et al., 2017). Additionally, the ability of senescent cells to secrete pro-inflammatory cytokines and chemokines (SASP) contributes to chronic inflammation and adverse paracrine effects (Krizhanovsky et al., 2008; Coppé et al., 2010). Finally, the tumorigenic potential and more 
aggressive behavior of post-senescent cells, including frequent epithelium-to-mesenchymal transition (EMT) and genomic instability, argues for the central involvement of senescent cells in disease recurrence (Sieben et al., 2018). To combat these potentially deleterious long-term effects of therapy-induced senescence, a new class of compounds, termed "senolytics" which selectively induce cell death in senescent cells, has been developed (Sieben et al., 2018).

In the current work, we investigated the utility of a two-hit sequential treatment approach, first with chemotherapy followed by senolysis, in head and neck cancer. We chose p53 wild-type HN30 cell line derived from pharynx and p53-null HN12 cell line derived from lymph node metastasis (Singchat et al., 2016), in consideration of the fact that $p 53$ is most commonly mutated in head and neck cancer patients (Leemans et al., 2011). Both cell lines showed a significant degree of senescence upon treatment with cisplatin by assessing multiple assays and markers (Figure 1). The delayed senescence in HN12 cell line likely reflects the p53-independent pathway(Mirzayans et al., 2012). For example, it has been shown that p16 plays a critical role in senescence induction in p53-null models (Mirzayans et al., 2012). We also confirmed senescence and tumor stasis induced by cisplatin treatment in a syngeneic mouse model (Figures 6B and 6D). Furthermore, the proliferative recovery from senescence was confirmed using fluorescence-activated cell sorting (FACS) and live cell imaging (Figure 2 and Videos) as well as in a mouse model (Figure 6B). These results further support the recent paradigm shift that therapy-induced senescence is transient, but not permanent, growth arrest, which may contribute to tumor recurrence from dormancy (Saleh, Bloukh, et al., 2020).

In order to overcome the survival mechanism which senescent cells maintain, our data indicates that a BCL-2/BCL-X $\mathrm{X}_{\mathrm{L}}$ inhibitor, ABT-263 (navitoclax) efficiently induces apoptosis following cisplatin treatment in in vitro and in vivo head and neck cancer models (Figures 3 and 
Figure 6D); these studies are consistent with previous reports showing effectiveness of ABT-263 in breast, lung, and prostate tumors (Zhu et al., 2015, 2016; Yosef et al., 2016; Grezella et al., 2018; Yabluchanskiy et al., 2020; Carpenter et al., 2021). We extensively investigated the selectivity of ABT-263, determining that this compound induces apoptosis only in the cisplatininduced senescence population, but not in the proliferating population (Saleh, Carpenter, et al., 2020) (Figures 3, S2A, S2B, and S2C). Additionally, our growth curve data with multiple exposures to cisplatin after proliferative recovery confirms that ABT-263 shows selectivity for the cells that are exposed to a second dose of cisplatin after recovery, but not the population recovered from the first cisplatin exposure (Figure S2E).

In mechanistic studies, we showed that (i) BCL- $\mathrm{X}_{\mathrm{L}}$ is the primary target for apoptosis induce by ABT-263 in senescent cells (Figure 4), and that (ii) the inhibition of BCL-X $/$ BAX interaction by ABT-263 followed by BAX activation is critical for this apoptosis induction (Figure 5). We and others have shown that $B C L-X_{L}$ expression increases gradually after senescence induction (Hayward et al., 2003; Saleh, Carpenter, et al., 2020; Mas-Bargues et al., 2021) and the sensitization induced by ABT-263 is BCL- $\mathrm{X}_{\mathrm{L}}$-dependent in breast and lung tumors (Saleh, Carpenter, et al., 2020). Our results indicate that BAX, but not BAK, is a critical pro-apoptotic protein for ABT-263-induced apoptosis in senescent cells in which the level of BCL-XL is induced and BAX is accumulated at the mitochondria. It has been shown that an increase of BCL-XL levels by overexpression leads to an increase of BAX at the mitochondria and sensitizes cells treated with ABT-737, a prototype BCL-2/BCL-X $\mathrm{L}$ inhibitor of ABT-263, to apoptosis (Renault et al., 2015). We speculate that the physiological levels of BCL- $\mathrm{X}_{\mathrm{L}}$ increased by senescence induction also led to BAX accumulation at the mitochondria, which shifts the dependency of ABT-263-induced apoptosis toward BAX. Consistently, studies have shown that BCL-XL is qualitatively and 
quantitively ten times more active than BCL-2 and is more effective in apoptosis inhibition (Wang et al., 2004; Fiebig et al., 2006). Moreover, the majority of head and neck cancer patients' tumor biopsies have shown a significant up-regulation in BCL- $\mathrm{X}_{\mathrm{L}}$ but not BCL-2 protein levels. BCL- $\mathrm{X}_{\mathrm{L}}$ levels was shown to be directly associated with worse therapy outcomes, whereas BCL-2 positive tumors, even after locoregional metastasis, demonstrated better therapy outcomes (Pena et al., 1999). Carter et.al also showed that BCL-XL is significantly overexpressed in head and neck cancer patients' tumor samples, while BCL-2 levels does not show any increase (Carter et al., 2019). These data suggest that BCL-X $\mathrm{X}_{\mathrm{L}}$ would play a major role, particularly in head and neck cancer, for drug sensitivity and treatment outcome. However, more additional work is needed to define the precise role(s) of BCL-X and BCL-2, since our findings in this report along with publications in this area clearly show that BCL-2 and BCL- $\mathrm{X}_{\mathrm{L}}$ are functionally distinct.

Our data with a syngeneic mouse model (Figure 6) clearly indicate that two rounds of sequential cisplatin followed by ABT-263 treatment has a distinct therapeutic benefit with delayed tumor recurrence and longer survival. Cycling treatments with drugs and/or radiation are common procedure and often show clinical benefits. One concern regarding ABT-263 in the clinic is the thrombocytopenia that has been a predominant dose limiting toxicity as both a monotherapy and in combination. This has been managed successfully in several recent trials, allowing for tolerated and biologically active combinations with kinase inhibitors such as Osimertinib (Bertino et al., 2021) and ruxolitinib (Harrison et al., 2019). However, neutropenia has been reported as a dose limiting toxicity when navitoclax was administered with chemotherapy (Puglisi et al., 2011); this toxicity has been particularly limiting for these combinations, none of which have progressed beyond Phase 1. Our data indicate that sequential exposures to ABT-263 after cisplatin treatment can effectively reduce tumor burden, and therefore alleviate the need to dose both agents 
concomitantly. This sequential dosing approach thus has the potential to effectively treat head and neck cancer patients while circumventing the limiting hematological toxicity that would be anticipated by simultaneous dosing of the two agents. Next generation BCL-2/BCL- $\mathrm{X}_{\mathrm{L}}$ inhibitors such as AZD0466 (Patterson et al., 2021), APG-1252 (Lakhani et al., 2018), and DT2216 (BCL$\mathrm{X}_{\mathrm{L}}$-PROTAC) (He et al., 2020) have been designed to mitigate thrombocytopenia and clinical trials have recently started with these agents. Thus, these compounds also need to be verified as senolytics to be combined with existing chemotherapy/targeting drugs in the future. It is also imperative to determine the senolytic efficacy following chemoradiation, which is commonly used as the first line treatment for HNSCC patients.

Taken together, our study provides a clear foundation upon which to develop therapeutic approaches for senescence clearance to potentially prevent or delay cancer relapse in HNSCC. Additionally, our in-vitro and in-vivo data show that sequential treatment of cisplatin and navitoclax can provide a potentially effective treatment strategy with mitigated toxicity for HNSCC patients. However, there are still key questions that need to be answered in future studies, such as the mechanistic basis for recovery from senescence, and the potential interplay between navitoclax and the immune system. Furthermore, studies in progress suggest that navitoclax may not be effective in cisplatin-resistant head and neck cancer models; consequently, we are in the process of identifying alternative senolytic strategies for eliminating the resistant population as well as testing senolytics against chemoradiation, the standard of care in head and neck cancer. 


\section{Acknowledgments:}

Tissue sectioning was provided by the VCU Tissue and Data Acquisition and Analysis Core (TDAAC) Facility. All flow cytometry data were generated at the VCU Massey Cancer Center Flow Cytometry Shared Resource.

\section{Author Contributions:}

Participated in research design: Gewirtz D, Harada H, Ahmadinejad F.

Conducted experiments: Ahmadinejad F, Bos T, Hu B, Britt E.

Contributed new reagents or analytic tools: Faber A, Koblinski J, Souers A, Leverson J.

Performed data analysis: Gewirtz D, Harada H, Ahmadinejad F, Bos T.

Wrote or contributed to the writing of the manuscript: Gewirtz D, Harada H, Ahmadinejad F, Bos

T, Souers A. 


\section{References}

Alotaibi M, Sharma K, Saleh T, Povirk LF, Hendrickson EA, and Gewirtz DA (2016) Radiosensitization by PARP Inhibition in DNA Repair Proficient and Deficient Tumor Cells: Proliferative Recovery in Senescent Cells. Radiat Res 185:229.

Ang KK, Zhang Q, Rosenthal DI, Nguyen-Tan PF, Sherman EJ, Weber RS, Galvin JM, Bonner JA, Harris J, ElNaggar AK, Gillison ML, Jordan RC, Konski AA, Thorstad WL, Trotti A, Beitler JJ, Garden AS, Spanos WJ, Yom SS, and Axelrod RS (2014) Randomized Phase III Trial of Concurrent Accelerated Radiation Plus Cisplatin With or Without Cetuximab for Stage III to IV Head and Neck Carcinoma: RTOG 0522. J Clin Oncol 32:2940-2950.

Argiris A, Karamouzis MV, Raben D, and Ferris RL (2008) Head and neck cancer. The Lancet 371:16951709.

Baker DJ, Wijshake T, Tchkonia T, LeBrasseur NK, Childs BG, van de Sluis B, Kirkland JL, and van Deursen JM (2011) Clearance of p16Ink4a-positive senescent cells delays ageing-associated disorders. Nature 479:232-236.

Basu A, and Krishnamurthy S (2010) Cellular Responses to Cisplatin-Induced DNA Damage. J Nucleic Acids 2010:1-16.

Beausejour CM (2003) Reversal of human cellular senescence: roles of the p53 and p16 pathways. EMBO J 22:4212-4222.

Bertino EM, Gentzler RD, Clifford S, Kolesar J, Muzikansky A, Haura EB, Piotrowska Z, Camidge DR, Stinchcombe TE, Hann C, Malhotra J, Villaruz LC, Paweletz CP, Lau CL, Sholl L, Takebe N, Moscow JA, Shapiro GI, Jänne PA, and Oxnard GR (2021) Phase IB Study of Osimertinib in Combination with Navitoclax in EGFR -mutant NSCLC Following Resistance to Initial EGFR Therapy (ETCTN 9903). Clin Cancer Res 27:1604-1611.

Carpenter V, Saleh T, Min Lee S, Murray G, Reed J, Souers A, Faber AC, Harada H, and Gewirtz DA (2021) Androgen-deprivation induced senescence in prostate cancer cells is permissive for the development of castration-resistance but susceptible to senolytic therapy. Biochem Pharmacol 193:114765.

Carter RJ, Milani M, Butterworth M, Alotibi A, Harper N, Yedida G, Greaves G, Al-Zebeeby A, Jorgensen AL, Schache AG, Risk JM, Shaw RJ, Jones TM, Sacco JJ, Hurlstone A, Cohen GM, and Varadarajan $S$ (2019) Exploring the potential of BH3 mimetic therapy in squamous cell carcinoma of the head and neck. Cell Death Dis 10:912.

Chen J, Jin S, Abraham V, Huang X, Liu B, Mitten MJ, Nimmer P, Lin X, Smith M, Shen Y, Shoemaker AR, Tahir SK, Zhang H, Ackler SL, Rosenberg SH, Maecker H, Sampath D, Leverson JD, Tse C, and Elmore SW (2011) The Bcl-2/Bcl-X L /Bcl-w Inhibitor, Navitoclax, Enhances the Activity of Chemotherapeutic Agents In Vitro and In Vivo. Mol Cancer Ther 10:2340-2349. 
Chitikova ZV, Gordeev SA, Bykova TV, Zubova SG, Pospelov VA, and Pospelova TV (2014) Sustained activation of DNA damage response in irradiated apoptosis-resistant cells induces reversible senescence associated with mTOR downregulation and expression of stem cell markers. Cell Cycle 13:1424-1439.

Chow LQM (2020) Head and Neck Cancer. N Engl J Med 382:60-72.

Coppé J-P, Desprez P-Y, Krtolica A, and Campisi J (2010) The Senescence-Associated Secretory Phenotype: The Dark Side of Tumor Suppression. Annu Rev Pathol Mech Dis 5:99-118.

Cramer JD, Burtness B, Le QT, and Ferris RL (2019) The changing therapeutic landscape of head and neck cancer. Nat Rev Clin Oncol 16:669-683.

Debacq-Chainiaux F, Erusalimsky JD, Campisi J, and Toussaint O (2009) Protocols to detect senescenceassociated beta-galactosidase (SA-ßgal) activity, a biomarker of senescent cells in culture and in vivo. Nat Protoc 4:1798-1806.

Demaria M, O'Leary MN, Chang J, Shao L, Liu S, Alimirah F, Koenig K, Le C, Mitin N, Deal AM, Alston S, Academia EC, Kilmarx S, Valdovinos A, Wang B, de Bruin A, Kennedy BK, Melov S, Zhou D, Sharpless NE, Muss H, and Campisi J (2017) Cellular Senescence Promotes Adverse Effects of Chemotherapy and Cancer Relapse. Cancer Discov 7:165-176.

Dimri GP, Lee X, Basile G, Acosta M, Scott G, Roskelley C, Medrano EE, Linskens M, Rubelj I, and PereiraSmith O (1995) A biomarker that identifies senescent human cells in culture and in aging skin in vivo. Proc Natl Acad Sci 92:9363-9367.

Dirac AMG, and Bernards R (2003) Reversal of Senescence in Mouse Fibroblasts through Lentiviral Suppression of p53. J Biol Chem 278:11731-11734.

Donà MG, Rollo F, Pichi B, Spriano G, Moretto S, Covello R, Pellini R, and Benevolo M (2020) Evolving Profile of HPV-Driven Oropharyngeal Squamous Cell Carcinoma in a National Cancer Institute in Italy: A 10-Year Retrospective Study. Microorganisms 8:1498.

Duy C, Li M, Teater M, Meydan C, Garrett-Bakelman FE, Lee TC, Chin CR, Durmaz C, Kawabata KC, Dhimolea E, Mitsiades CS, Doehner H, D'Andrea RJ, Becker MW, Paietta EM, Mason CE, Carroll M, and Melnick AM (2021) Chemotherapy Induces Senescence-Like Resilient Cells Capable of Initiating AML Recurrence. Cancer Discov candisc;2159-8290.CD-20-1375v2.

Elmore LW (2005) Evasion of a Single-Step, Chemotherapy-Induced Senescence in Breast Cancer Cells: Implications for Treatment Response. Clin Cancer Res 11:2637-2643.

Ewald JA, Desotelle JA, Wilding G, and Jarrard DF (2010) Therapy-Induced Senescence in Cancer. JNCI J Natl Cancer Inst 102:1536-1546.

Farris FF, Dedrick RL, and King FG (1988) Cisplatin pharmacokinetics: applications of a physiological model. Toxicol Lett 43:117-137. 
Fiebig AA, Zhu W, Hollerbach C, Leber B, and Andrews DW (2006) Bcl-XL is qualitatively different from and ten times more effective than $\mathrm{Bcl}-2$ when expressed in a breast cancer cell line. BMC Cancer 6:213.

Gibson MK, Li Y, Murphy B, Hussain MHA, DeConti RC, Ensley J, and Forastiere AA (2005) Randomized Phase III Evaluation of Cisplatin Plus Fluorouracil Versus Cisplatin Plus Paclitaxel in Advanced Head and Neck Cancer (E1395): An Intergroup Trial of the Eastern Cooperative Oncology Group. J Clin Oncol 23:3562-3567.

Goss PE, and Chambers AF (2010) Does tumour dormancy offer a therapeutic target? Nat Rev Cancer 10:871-877.

Grezella C, Fernandez-Rebollo E, Franzen J, Ventura Ferreira MS, Beier F, and Wagner W (2018) Effects of senolytic drugs on human mesenchymal stromal cells. Stem Cell Res Ther 9:108.

Harrison CN, Garcia JS, Mesa RA, Somervaille TC, Komrokji RS, Pemmaraju N, Jamieson C, Papadantonakis N, Foran JM, O'Connell CL, Holes L, Jia J, Harb J, Hutti J, and Prchal JT (2019) Results from a Phase 2 Study of Navitoclax in Combination with Ruxolitinib in Patients with Primary or Secondary Myelofibrosis. Blood 134:671-671.

Hayward RL, Macpherson JS, Cummings J, Monia BP, Smyth JF, and Jodrell DI (2003) Antisense Bcl-xl Down-Regulation Switches the Response to Topoisomerase I Inhibition from Senescence to Apoptosis in Colorectal Cancer Cells, Enhancing Global Cytotoxicity. Clin Cancer Res 9:2856.

He Y, Koch R, Budamagunta V, Zhang P, Zhang Xuan, Khan S, Thummuri D, Ortiz YT, Zhang Xin, Lv D, Wiegand JS, Li W, Palmer AC, Zheng G, Weinstock DM, and Zhou D (2020) DT2216-a Bcl-xLspecific degrader is highly active against Bcl-xL-dependent T cell lymphomas. J Hematol OncolJ Hematol Oncol 13:95.

Hernandez-Segura A, de Jong TV, Melov S, Guryev V, Campisi J, and Demaria M (2017) Unmasking Transcriptional Heterogeneity in Senescent Cells. Curr Biol 27:2652-2660.e4.

Hernandez-Segura A, Nehme J, and Demaria M (2018) Hallmarks of Cellular Senescence. Trends Cell Biol 28:436-453.

Jeon JH, Kim SK, Kim HJ, Chang J, Ahn CM, and Chang YS (2008) Insulin-like growth factor-1 attenuates cisplatin-induced $\mathrm{\gamma H} 2 \mathrm{AX}$ formation and DNA double-strand breaks repair pathway in non-small cell lung cancer. Cancer Lett 272:232-241.

Kareva I (2016) Escape from tumor dormancy and time to angiogenic switch as mitigated by tumorinduced stimulation of stroma. J Theor Biol 395:11-22.

Kim RS, Avivar-Valderas A, Estrada Y, Bragado P, Sosa MS, Aguirre-Ghiso JA, and Segall JE (2012) Dormancy Signatures and Metastasis in Estrogen Receptor Positive and Negative Breast Cancer. PLOS ONE 7:e35569.

Krizhanovsky V, Yon M, Dickins RA, Hearn S, Simon J, Miething C, Yee H, Zender L, and Lowe SW (2008) Senescence of Activated Stellate Cells Limits Liver Fibrosis. Cell 134:657-667. 
Lafontaine J, Cardin GB, Malaquin N, Boisvert J-S, Rodier F, and Wong P (2021) Senolytic Targeting of Bcl2 Anti-Apoptotic Family Increases Cell Death in Irradiated Sarcoma Cells. Cancers 13:386.

Lakhani NJ, Rasco DW, Tolcher AW, Huang Y, Ji J, Wang H, Dong Q, Men L, O'Rourke TJ, Chandana SR, Amaya A, Cole Y, Kaiser B, Mays TA, Patnaik A, Papadopoulos KP, Yang D, and Zhai Y (2018) A phase I study of novel dual Bcl-2/Bcl-xL inhibitor APG-1252 in patients with advanced small cell lung cancer (SCLC) or other solid tumor. J Clin Oncol 36:2594-2594.

Lambrecht M, Dirix P, Van den Bogaert W, and Nuyts S (2009) Incidence of isolated regional recurrence after definitive (chemo-) radiotherapy for head and neck squamous cell carcinoma. Radiother Oncol 93:498-502.

Leemans CR, Braakhuis BJM, and Brakenhoff RH (2011) The molecular biology of head and neck cancer. Nat Rev Cancer 11:9-22.

Mas-Bargues C, Borrás C, and Viña J (2021) Bcl-xL as a Modulator of Senescence and Aging. Int J Mol Sci 22:1527.

Mérino D, Khaw SL, Glaser SP, Anderson DJ, Belmont LD, Wong C, Yue P, Robati M, Phipson B, Fairlie WD, Lee EF, Campbell KJ, Vandenberg CJ, Cory S, Roberts AW, Ludlam MJC, Huang DCS, and Bouillet $\mathrm{P}$ (2012) Bcl-2, Bcl-xL, and Bcl-w are not equivalent targets of ABT-737 and navitoclax (ABT-263) in lymphoid and leukemic cells. Blood 119:5807-5816.

Mirzayans R, Andrais B, Hansen G, and Murray D (2012) Role of p16 INK4A in Replicative Senescence and DNA Damage-Induced Premature Senescence in p53-Deficient Human Cells. Biochem Res Int 2012:1-8.

Morgan TM, Lange PH, Porter MP, Lin DW, Ellis WJ, Gallaher IS, and Vessella RL (2009) Disseminated Tumor Cells in Prostate Cancer Patients after Radical Prostatectomy and without Evidence of Disease Predicts Biochemical Recurrence. Clin Cancer Res 15:677-683.

Nardella C, Clohessy JG, Alimonti A, and Pandolfi PP (2011) Pro-senescence therapy for cancer treatment. Nat Rev Cancer 11:503-511.

Oltersdorf T, Elmore SW, Shoemaker AR, Armstrong RC, Augeri DJ, Belli BA, Bruncko M, Deckwerth TL, Dinges J, Hajduk PJ, Joseph MK, Kitada S, Korsmeyer SJ, Kunzer AR, Letai A, Li C, Mitten MJ, Nettesheim DG, Ng S, Nimmer PM, O'Connor JM, Oleksijew A, Petros AM, Reed JC, Shen W, Tahir SK, Thompson CB, Tomaselli KJ, Wang B, Wendt MD, Zhang H, Fesik SW, and Rosenberg SH (2005) An inhibitor of $\mathrm{Bcl}-2$ family proteins induces regression of solid tumours. Nature 435:677-681.

Patterson CM, Balachander SB, Grant I, Pop-Damkov P, Kelly B, McCoull W, Parker J, Giannis M, Hill KJ, Gibbons FD, Hennessy EJ, Kemmitt P, Harmer AR, Gales S, Purbrick S, Redmond S, Skinner M, Graham L, Secrist JP, Schuller AG, Wen S, Adam A, Reimer C, Cidado J, Wild M, Gangl E, Fawell SE, Saeh J, Davies BR, Owen DJ, and Ashford MB (2021) Design and optimisation of dendrimerconjugated $\mathrm{BCl}-2 / \mathrm{xL}$ inhibitor, AZD0466, with improved therapeutic index for cancer therapy. Commun Biol 4:112. 
Pena JC, Thompson CB, Recant W, Vokes EE, and Rudin CM (1999) Bcl-xL and Bcl-2 expression in squamous cell carcinoma of the head and neck. Cancer 85:164-170.

Pérez-Mancera PA, Young ARJ, and Narita M (2014) Inside and out: the activities of senescence in cancer. Nat Rev Cancer 14:547-558.

Phi LTH, Sari IN, Yang Y-G, Lee S-H, Jun N, Kim KS, Lee YK, and Kwon HY (2018) Cancer Stem Cells (CSCs) in Drug Resistance and their Therapeutic Implications in Cancer Treatment. Stem Cells Int 2018:1-16.

Puglisi M, Molife LR, de Jonge MJ, Khan KH, Doorn L van, Forster MD, Blanco M, Gutierrez M, Franklin C, Busman T, Yang J, and Eskens FA (2021) A Phase I study of the safety, pharmacokinetics and efficacy of navitoclax plus docetaxel in patients with advanced solid tumors. Future Oncol fon2021-0140.

Puglisi M, van Doorn L, Blanco-Codesido M, De Jonge MJ, Moran K, Yang J, Busman T, Franklin C, Mabry M, Krivoshik A, Humerickhouse R, Molife LR, and Eskens F (2011) A phase I safety and pharmacokinetic (PK) study of navitoclax (N) in combination with docetaxel (D) in patients (pts) with solid tumors. J Clin Oncol 29:2518-2518.

Puig P-E, Guilly M-N, Bouchot A, Droin N, Cathelin D, Bouyer F, Favier L, Ghiringhelli F, Kroemer G, and Solary E (2008) Tumor cells can escape DNA-damaging cisplatin through DNA endoreduplication and reversible polyploidy. Cell Biol Int 32:1031-1043.

Raffo AJ, Perlman H, Chen MW, Day ML, Streitman JS, and Buttyan R (1995) Overexpression of bcl-2 protects prostate cancer cells from apoptosis in vitro and confers resistance to androgen depletion in vivo. Cancer Res 55:4438-4445.

Rebbaa A (2005) Targeting senescence pathways to reverse drug resistance in cancer. Cancer Lett 219:1-13.

Renault TT, Teijido O, Missire F, Ganesan YT, Velours G, Arokium H, Beaumatin F, Llanos R, Athané A, Camougrand N, Priault M, Antonsson B, Dejean LM, and Manon S (2015) Bcl-xL stimulates Bax relocation to mitochondria and primes cells to ABT-737. Int J Biochem Cell Biol 64:136-146.

Rezaee M, Sanche L, and Hunting DJ (2013) Cisplatin Enhances the Formation of DNA Single- and Double-Strand Breaks by Hydrated Electrons and Hydroxyl Radicals. Radiat Res 179:323-331.

Roberson RS, Kussick SJ, Vallieres E, Chen S-YJ, and Wu DY (2005) Escape from Therapy-Induced Accelerated Cellular Senescence in p53-Null Lung Cancer Cells and in Human Lung Cancers. Cancer Res 65:2795-2803.

Roberts AW, Wilson W, Gandhi L, O'Connor OA, Rudin CM, Brown JR, Xiong H, Chiu Y, Enschede S, and Krivoshik AP (2009) Ongoing phase I studies of ABT-263: Mitigating Bcl- $X_{L}$ induced thrombocytopenia with lead-in and continuous dosing. J Clin Oncol 27:3505-3505.

Rudin CM, Hann CL, Garon EB, Ribeiro de Oliveira M, Bonomi PD, Camidge DR, Chu Q, Giaccone G, Khaira D, Ramalingam SS, Ranson MR, Dive C, McKeegan EM, Chyla BJ, Dowell BL, Chakravartty A, Nolan CE, Rudersdorf N, Busman TA, Mabry MH, Krivoshik AP, Humerickhouse RA, Shapiro GI, 
Molecular Pharmacology Fast Forward. Published on December 14, 2021 as DOI: 10.1124/molpharm.121.000354 This article has not been copyedited and formatted. The final version may differ from this version.

and Gandhi L (2012) Phase II Study of Single-Agent Navitoclax (ABT-263) and Biomarker Correlates in Patients with Relapsed Small Cell Lung Cancer. Clin Cancer Res 18:3163-3169.

Saleh T, Bloukh S, Carpenter VJ, Alwohoush E, Bakeer J, Darwish S, Azab B, and Gewirtz DA (2020) Therapy-Induced Senescence: An “Old" Friend Becomes the Enemy. Cancers 12:822.

Saleh T, Carpenter VJ, Tyutyunyk-Massey L, Murray G, Leverson JD, Souers AJ, Alotaibi MR, Faber AC, Reed J, Harada H, and Gewirtz DA (2020) Clearance of therapy-induced senescent tumor cells by the senolytic ABT-263 via interference with BCL-X $L-B A X$ interaction. Mol Oncol 14:2504-2519.

Saleh T, Tyutyunyk-Massey L, Murray GF, Alotaibi MR, Kawale AS, Elsayed Z, Henderson SC, Yakovlev V, Elmore LW, Toor A, Harada H, Reed J, Landry JW, and Gewirtz DA (2019) Tumor cell escape from therapy-induced senescence. Biochem Pharmacol 162:202-212.

Seluanov A, Gorbunova V, Falcovitz A, Sigal A, Milyavsky M, Zurer I, Shohat G, Goldfinger N, and Rotter V (2001) Change of the Death Pathway in Senescent Human Fibroblasts in Response to DNA Damage Is Caused by an Inability To Stabilize p53. Mol Cell Biol 21:1552-1564.

Sharma K, Goehe RW, Di X, Hicks MA, Torti SV, Torti FM, Harada H, and Gewirtz DA (2014) A novel cytostatic form of autophagy in sensitization of non-small cell lung cancer cells to radiation by vitamin D and the vitamin D analog, EB 1089. Autophagy 10:2346-2361.

Sharpless NE, and Sherr CJ (2015) Forging a signature of in vivo senescence. Nat Rev Cancer 15:397-408.

Shay JW, and Roninson IB (2004) Hallmarks of senescence in carcinogenesis and cancer therapy. Oncogene 23:2919-2933.

Shoemaker AR, Mitten MJ, Adickes J, Oleksijew A, Zhang H, Bauch J, Marsh K, Frost DJ, Madar D, Tse C, Fesik SW, Rosenberg SH, and Elmore SW (2006) The Bcl-2 Family Inhibitor ABT-263 Shows Significant but Reversible Thrombocytopenia in Mice. Blood 108:1107-1107.

Sieben CJ, Sturmlechner I, van de Sluis B, and van Deursen JM (2018) Two-Step Senescence-Focused Cancer Therapies. Trends Cell Biol 28:723-737.

Singchat W, Hitakomate E, Rerkarmnuaychoke B, Suntronpong A, Fu B, Bodhisuwan W, Peyachoknagul S, Yang F, Koontongkaew S, and Srikulnath K (2016) Genomic Alteration in Head and Neck Squamous Cell Carcinoma (HNSCC) Cell Lines Inferred from Karyotyping, Molecular Cytogenetics, and Array Comparative Genomic Hybridization. PLOS ONE 11:e0160901.

Sosa MS, Bragado P, and Aguirre-Ghiso JA (2014) Mechanisms of disseminated cancer cell dormancy: an awakening field. Nat Rev Cancer 14:611-622.

Triana-Martínez F, Loza MI, and Domínguez E (2020) Beyond Tumor Suppression: Senescence in Cancer Stemness and Tumor Dormancy. Cells 9:346.

Tse C, Shoemaker AR, Adickes J, Anderson MG, Chen J, Jin S, Johnson EF, Marsh KC, Mitten MJ, Nimmer P, Roberts L, Tahir SK, Xiao Y, Yang X, Zhang H, Fesik S, Rosenberg SH, and Elmore SW (2008) ABT-263: A Potent and Orally Bioavailable Bcl-2 Family Inhibitor. Cancer Res 68:3421-3428. 
Urien S, and Lokiec F (2004) Population pharmacokinetics of total and unbound plasma cisplatin in adult patients. Br J Clin Pharmacol 57:756-763.

Walens A, DiMarco AV, Lupo R, Kroger BR, Damrauer JS, and Alvarez JV (2019) CCL5 promotes breast cancer recurrence through macrophage recruitment in residual tumors. eLife 8:e43653.

Wang $\mathrm{H}$, Stoecklein NH, Lin PP, and Gires O (2017) Circulating and disseminated tumor cells: diagnostic tools and therapeutic targets in motion. Oncotarget 8:1884-1912.

Wang Q, Wu PC, Dong DZ, Ivanova I, Chu E, Zeliadt S, Vesselle H, and Wu DY (2013) Polyploidy road to therapy-induced cellular senescence and escape. Int J Cancer 132:1505-1515.

Wang X, Zhang J, Kim HP, Wang Y, Choi AMK, and Ryter SW (2004) Bcl-X L disrupts death-inducing signal complex formation in plasma membrane induced by hypoxia/reoxygenation. FASEB J 18:18261833.

Wiley CD, Flynn JM, Morrissey C, Lebofsky R, Shuga J, Dong X, Unger MA, Vijg J, Melov S, and Campisi J (2017) Analysis of individual cells identifies cell-to-cell variability following induction of cellular senescence. Aging Cell 16:1043-1050.

Wu C-Y, Lee C-L, Wu C-F, Fu J-Y, Yang C-T, Wen C-T, Liu Y-H, Liu H-P, and Hsieh JC-H (2020) Circulating Tumor Cells as a Tool of Minimal Residual Disease Can Predict Lung Cancer Recurrence: A longitudinal, Prospective Trial. Diagnostics 10:144.

Yabluchanskiy A, Tarantini S, Balasubramanian P, Kiss T, Csipo T, Fülöp GA, Lipecz A, Ahire C, DelFavero J, Nyul-Toth A, Sonntag WE, Schwartzman ML, Campisi J, Csiszar A, and Ungvari Z (2020) Pharmacological or genetic depletion of senescent astrocytes prevents whole brain irradiationinduced impairment of neurovascular coupling responses protecting cognitive function in mice. GeroScience 42:409-428.

Yang L, Fang J, and Chen J (2017) Tumor cell senescence response produces aggressive variants. Cell Death Discov 3:17049.

Yeh AC, and Ramaswamy S (2015) Mechanisms of Cancer Cell Dormancy--Another Hallmark of Cancer? Cancer Res 75:5014-5022.

Yosef R, Pilpel N, Tokarsky-Amiel R, Biran A, Ovadya Y, Cohen S, Vadai E, Dassa L, Shahar E, Condiotti R, Ben-Porath I, and Krizhanovsky V (2016) Directed elimination of senescent cells by inhibition of BCL-W and BCL-XL. Nat Commun 7:11190.

Zhu Y, Tchkonia T, Fuhrmann-Stroissnigg H, Dai HM, Ling YY, Stout MB, Pirtskhalava T, Giorgadze N, Johnson KO, Giles CB, Wren JD, Niedernhofer LJ, Robbins PD, and Kirkland JL (2016) Identification of a novel senolytic agent, navitoclax, targeting the Bcl-2 family of anti-apoptotic factors. Aging Cell 15:428-435.

Zhu Y, Tchkonia T, Pirtskhalava T, Gower AC, Ding H, Giorgadze N, Palmer AK, Ikeno Y, Hubbard GB, Lenburg M, O'Hara SP, LaRusso NF, Miller JD, Roos CM, Verzosa GC, LeBrasseur NK, Wren JD, Farr JN, Khosla S, Stout MB, McGowan SJ, Fuhrmann-Stroissnigg H, Gurkar AU, Zhao J, Colangelo D, Dorronsoro A, Ling YY, Barghouthy AS, Navarro DC, Sano T, Robbins PD, Niedernhofer L, and 
Molecular Pharmacology Fast Forward. Published on December 14, 2021 as DOI: 10.1124/molpharm.121.000354

This article has not been copyedited and formatted. The final version may differ from this version.

Kirkland JL (2015) The Achilles' heel of senescent cells: from transcriptome to senolytic drugs. Aging Cell 14:644-658. 


\section{Footnotes:}

This research was supported in part by the National Institutes of Health R03 CA235097 (to

H.H.), R01 CA239706 (to D.A.G. and H.H.) and the AADR Students Research Fellowship (to

E.B.). Services and products generated by the VCU Massey Cancer Center Cancer Mouse Model

Shared Resource were supported in part by funding from NIH/National Cancer Institute (NCI)

Cancer Center Support Grant P30 CA016059.

A.J.S. and J.D.L. are employees and shareholders of AbbVie. A.C.F. is a paid consultant for AbbVie. Other authors have an actual or perceived conflict of interest with the contents of this article. 
Figure 1. Cisplatin induces senescence-mediated growth arrest in HNSCC cells. A) Cell viability was monitored over a period of 12 days by trypan blue exclusion in HN30 and HN12 cells after 24 hours of exposure to 2, 5, and $10 \mu \mathrm{M}$ cisplatin. B) Cell cycle analysis of HN30 and HN12 cells at Day 5 after treatment with $5 \mu \mathrm{M}$ cisplatin for 24 hours. Cell cycle distribution is shown in the bar graphs. * $\mathrm{p} \leq$ $0.05, * * \mathrm{p} \leq 0.01, * * * \mathrm{p} \leq 0.001, * * * * \mathrm{p} \leq 0.0001$ indicate statistical significance of each condition compared to control as determined using Student's t-test. C) Cells were analyzed for increased expression of SA- $\beta$-gal using X-gal (20x objective, scale bar: $20 \mu \mathrm{m}$, bright field images) or $\mathrm{C}_{12}$ FDG (bar graphs) and increased SAHF formation by H3K9ME3 immunofluorescence (100x objective, scale bar: $5 \mu$ m, fluorescent images). Blue fluorescence indicates nuclear staining with DAPI, and green fluorescence reflects $\mathrm{H} 3 \mathrm{~K} 9 \mathrm{Me} 3$ immunostaining. Staining was performed 5 days after treatment with $5 \mu \mathrm{M}$ cisplatin for 24 hours. D) Western blotting for p53 and p21 in HN30 and HN12 cells at the indicated time points after cisplatin treatment. E) qRT-PCR for the SASP mRNAs IL-6, IL-8, and IL-1 $\beta$. RNA was extracted at Day 5 following cisplatin exposure. All images are representative fields or blots from at least three independent experiments, and all quantitative graphs are mean $\pm \mathrm{SD}$ from at least three independent experiments. * $\mathrm{p} \leq$ $0.05, * * \mathrm{p} \leq 0.01, * * * \mathrm{p} \leq 0.001, * * * * \mathrm{p} \leq 0.0001$ indicate statistical significance of each condition compared to control as determined using two-way ANOVA with Sidak's post hoc test. All images are representative fields or blots from three independent experiments $(n=3)$. 
Molecular Pharmacology Fast Forward. Published on December 14, 2021 as DOI: 10.1124/molpharm.121.000354 This article has not been copyedited and formatted. The final version may differ from this version. 
Figure 2. Proliferative recovery from cisplatin treatment in $\mathrm{HN} 30$ and $\mathrm{HN} 12$ cells is associated with the reduction of senescence-associated features. A) Histochemical SA- $\beta$-gal staining (20x objective, scale bar: $20 \mu \mathrm{m}$, bright field images). Cells were treated with 5uM cisplatin for 24 hours and stained for SA- $\beta$-gal activity at days 10 and 14 . Note that the enzyme activity declines with cellular proliferative recovery. B) qRT-PCR for the SASP mRNAs IL-6, IL-8, and IL-1 $\beta . * \mathrm{P} \leq 0.05$, **P $\leq$ 0.01 , and $* * * \mathrm{P} \leq 0.001$ indicate statistical significance of each condition compared to control as determined using two-way ANOVA with Sidak's post hoc test .C) Growth curve and D) SA- $\beta$-gal staining for high$\mathrm{C}_{12}$ FDG-positive HN30 and HN12 cells (enriched on Day 5 after cisplatin treatment). 


\section{Figure 3. ABT-263 induces apoptotic cell death in cisplatin-induced senescent cells. A) Growth} curves for cells treated with cisplatin followed by either vehicle or $2 \mu \mathrm{M}$ ABT-263 for 24 hours. Arrows indicate the time of ABT-263 treatment. B) Annexin-V/PI quantification of apoptosis induced by $2 \mu \mathrm{M}$ ABT-263 with overnight exposure 24 hours after drug removal (Day 7) in HN30 and HN12 cells after treatment with cisplatin. C) Western blots for cleaved-caspase 3 in HN30 and HN12 cells. Cells were treated with $5 \mathrm{uM}$ cisplatin followed by ABT-263 for 24 hours and harvested at day 7 . All images are representative fields or blots from at least three independent experiments, and all quantitative graphs are mean \pm SD from at least three independent experiments. $* \mathrm{p} \leq 0.05, * * \mathrm{p} \leq 0.01, * * * \mathrm{p} \leq 0.001, * * * * \mathrm{p} \leq 0.0001$ indicate statistical significance of each condition compared to control as determined using two-way ANOVA with Sidak's post hoc test. 
Figure 4. BCL-X $\mathrm{L}_{\mathrm{L}}$ is the primary target for ABT-263-induced senolysis. Growth curves for A) HN30 and B) HN12 cells treated with 5uM cisplatin followed by either vehicle, $2 \mu \mathrm{M}$ A-1155463 (Left) or ABT-199 (Right) for 24 hours. Arrows indicate timepoints of A-1155463 or ABT-199 treatment. C) and D) Apoptotic cell death was determined in HN30 andHN12 cells, respectively, by Annexin-V/PI staining followed by FACS analysis. $* * * \mathrm{p} \leq 0.001, * * * * \mathrm{p} \leq 0.0001$ indicate statistical significance of each condition compared to indicated condition as determined using two-way ANOVA with Sidak's post hoc test. 
Figure 5. ABT-263 induces senolytic activity through modulation of the $B A X / B C L-X_{L}$ interaction. A) HN30 cells were treated with cisplatin and harvested at the indicated times. B) HN12 cells were treated with $5 \mathrm{uM}$ cisplatin and harvested at Day 7. Total cell lysates were subjected to Western blotting with the indicated antibodies. C) HN30 shBAX, shBAK and shC (scrambled control) cells were treated with cisplatin $(5 \mu \mathrm{M})$ for 5 days. Total cell lysates were subjected to Western blotting with the indicated antibodies. D) Senescent cells in (C) were treated with ABT-263, ABT-199, A-1155463 (1 $\mu$ M each) for 24 hours and stained with trypan blue and X-gal activity. (10x objective, scale bar: $10 \mu \mathrm{m}$, bright field images). E) BAX is recruited to the mitochondria membrane upon ABT-263 treatment. HN30 cells were treated with cisplatin $(5 \mu \mathrm{M})$ for 5 days followed by ABT-263 $(1 \mu \mathrm{M})$ for 16 hours. The earlier time point allowed us to detect navitoclax effects on apoptosis regulatory proteins before apoptosis completion, which might have resulted in the degradation of select proteins. Mitochondria-enriched (heavy membrane) fractions were subjected to Western blotting with the indicated antibodies. F) ABT-263 disrupts the interactions of $\mathrm{BCL}-\mathrm{X}_{\mathrm{L}}$ and $\mathrm{BAX}$. $\mathrm{HN} 30$ cells were treated as in $(\mathrm{E})$, and total cell lysates were immunoprecipitated with anti-BCL- $\mathrm{X}_{\mathrm{L}}$ antibodies followed by Western blotting with the indicated antibodies. All images are representative fields or blots from three independent experiments $(\mathrm{n}=3)$, and all quantitative graphs are mean \pm SD from three independent experiments $(n=3)$. 


\section{Figure 6. Sequential administration of ABT-263 following cisplatin delays tumor recurrence}

in a syngeneic mouse model of OSCC. A) ABT-263 eliminates cisplatin-induced senescent mouse OSCC cells in vitro. Mouse OSCC 602 cells were treated with cisplatin $(2.5 \mu \mathrm{M}$, the dose efficiently induces senescence in this cell line) for 5 days followed by exposure to ABT-263 (1 $\mu \mathrm{M})$ for 24 hours. Cells were stained with trypan blue to investigate ABT-263 effectiveness. X-gal staining in SA- $\beta$-gal positive cells indicates senescence after cisplatin treatment. (10x objective, scale bar: $10 \mu \mathrm{m}$, bright field images). B) 602 cells were subcutaneously inoculated in C57BL/6 mice at the flank (Day 0). When tumors achieved a size of $\sim 100 \mathrm{~mm} 3$, mice were randomized into five groups (Day 13, N=6/group). Mice were treated with cisplatin $(5 \mathrm{mg} / \mathrm{kg})$ at Day 13, 16, 20 and 23, followed by ABT-263 (80 mg/kg) daily at Day 27-31 and Day 34-38. The second round of treatments was performed with cisplatin at Day 41,44 and 48 , followed with ABT-263 at Day 55-59 and Day 62-66. Tumor volume (B) was determined by caliper measurements and survival (C) was monitored by Kaplan-Meier curves. D) Tumors were excised after treatment with vehicle (control), cisplatin, ABT-263 or cisplatin followed by ABT-263. SA- $\beta$-gal activity was monitored by staining with X-gal, and DNA double-strand breaks repair and apoptosis were monitored by immunohistochemical staining with antibodies against $\gamma$-H2AX and cleaved-caspase-3, respectively $($ Original magnification $=20 \mathrm{X})$. Graphs are represented as mean \pm SEM. All tumor images are representative fields from four tumor slices $(n=3)$ taken from three mice per group $(n=3)$. 
Figure 7. Platelet cell count $(\mathbf{K} / \mu \mathrm{l})$ in mice treated with $\mathbf{A})$ vehicle, B) cisplatin alone, $\mathbf{C})$ ABT263 alone or $\mathbf{D}$ and $\mathbf{E}$ ) in combination with cisplatin over a period of 21 days. Control vs ABT, cisplatin, Combination A or B: $\mathrm{p}>0.05$ as determined using two-way ANOVA with Sidak's post hoc test. All quantitative graphs are mean \pm SD from at least three independent experiments. 


\section{Figure 1}

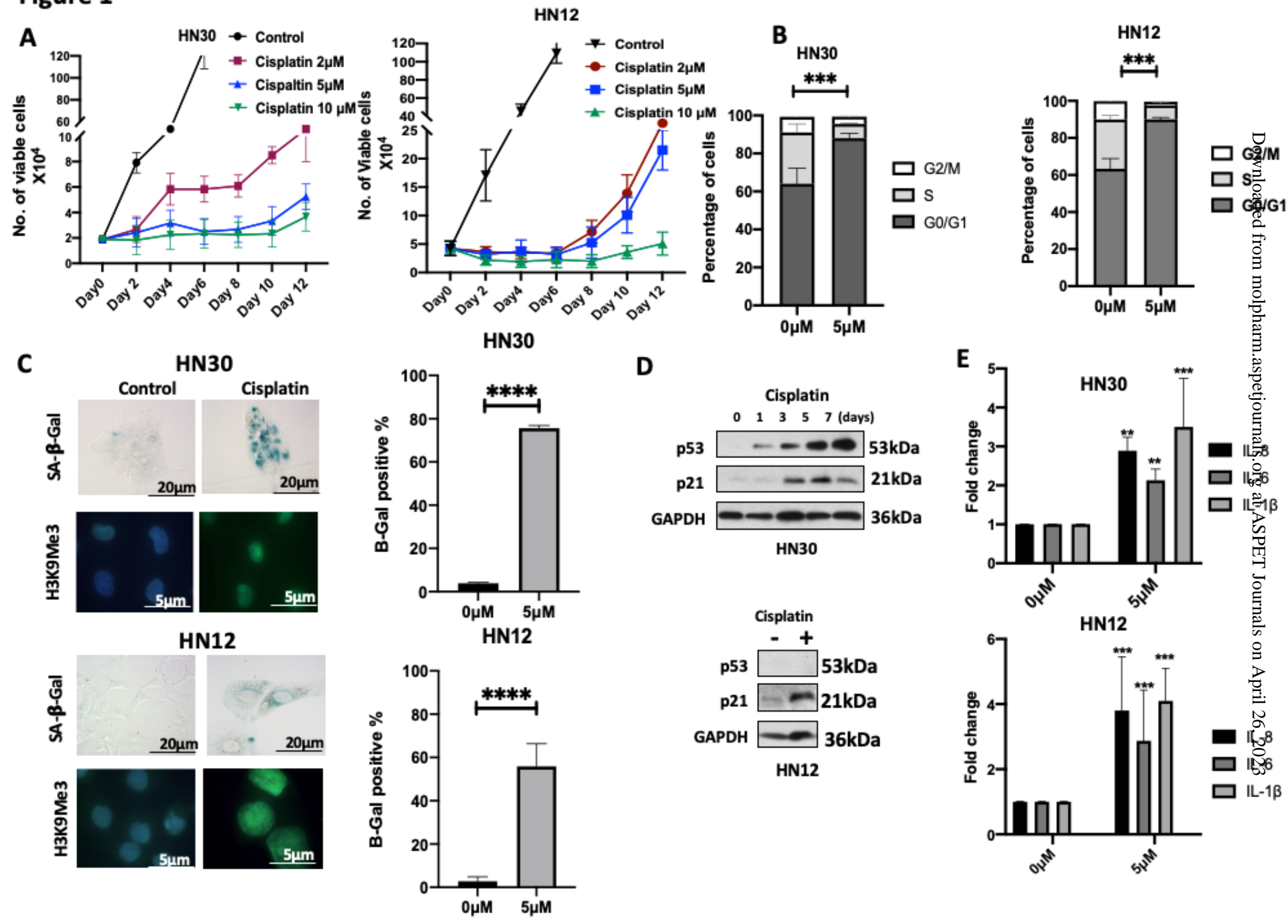


Figure 2

A

HN30

B

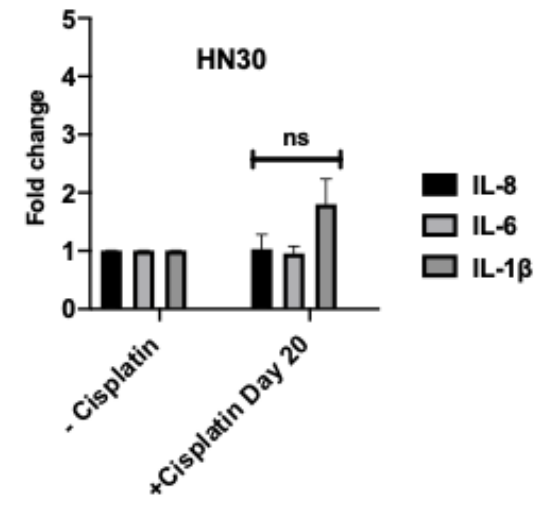

C

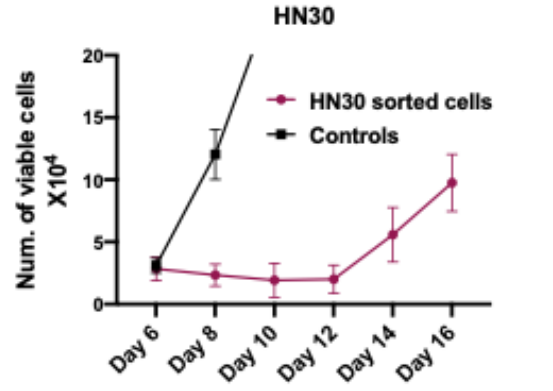

D
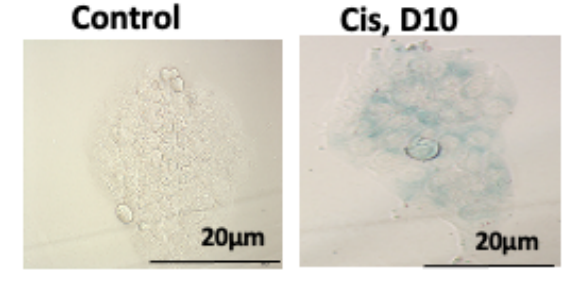

Cis, D14
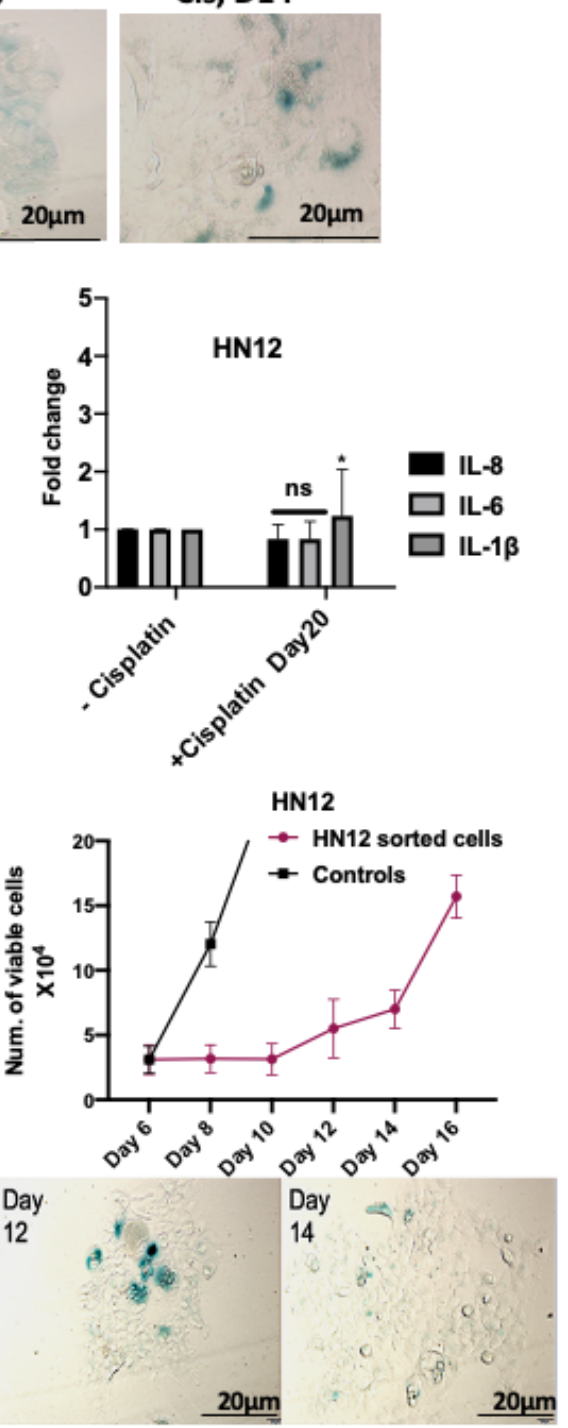
Figure 3

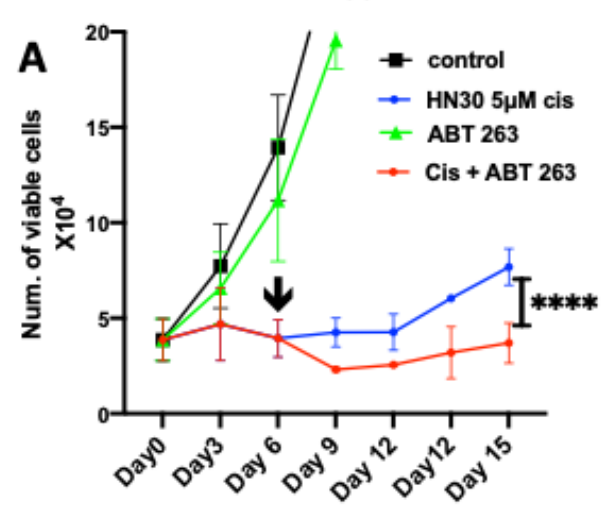

HN30

B

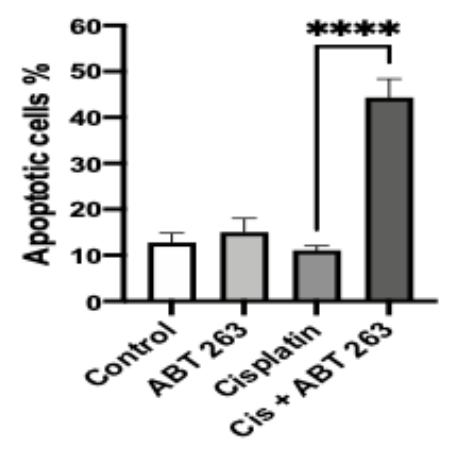

C

Cisplatin D7

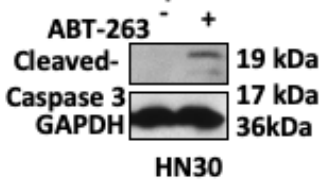

HN12
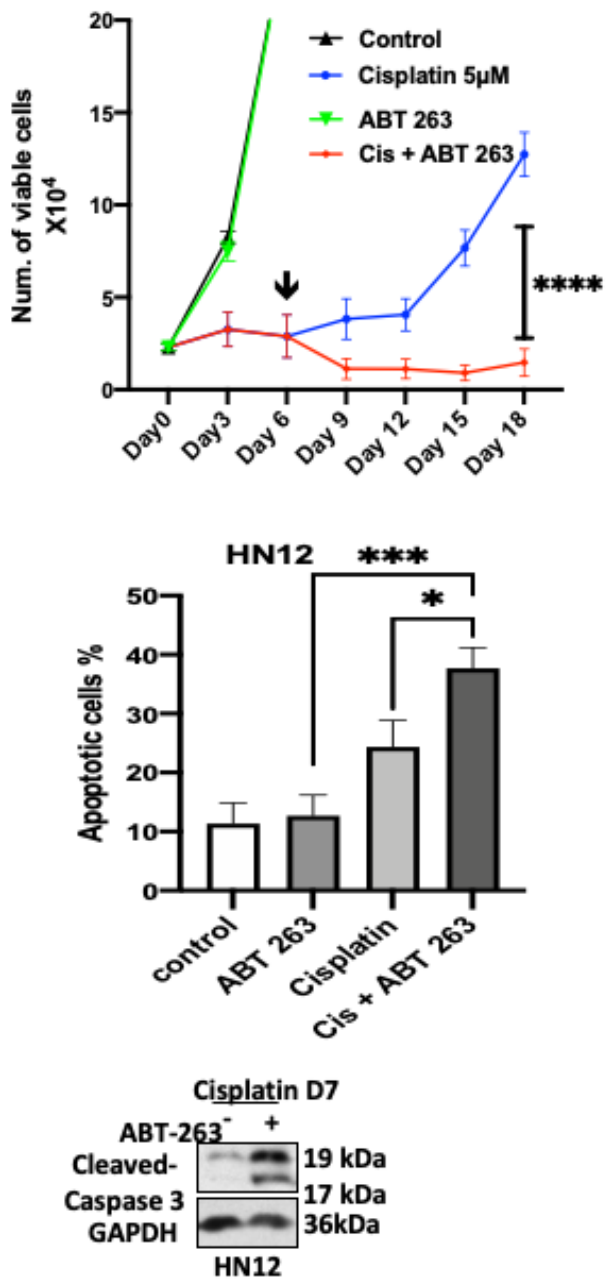


\section{Figure 4}

A

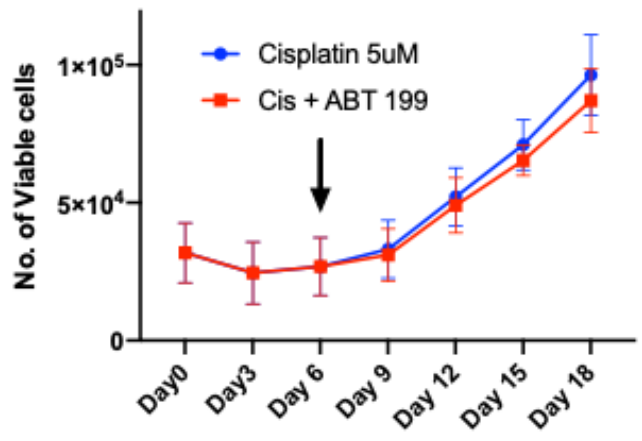

B

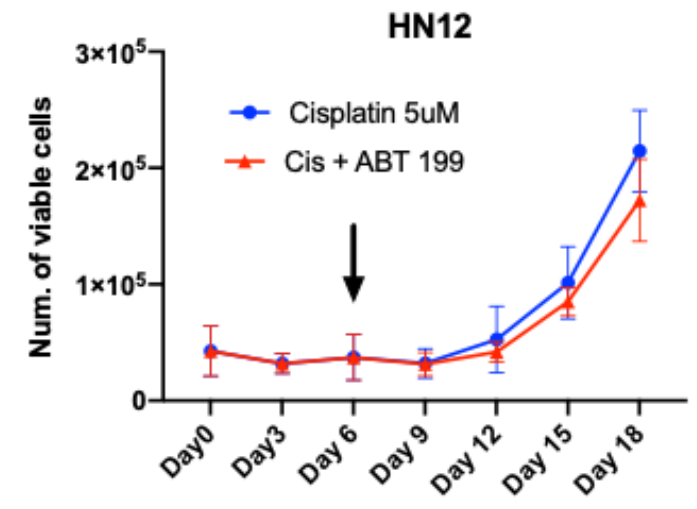

HN30
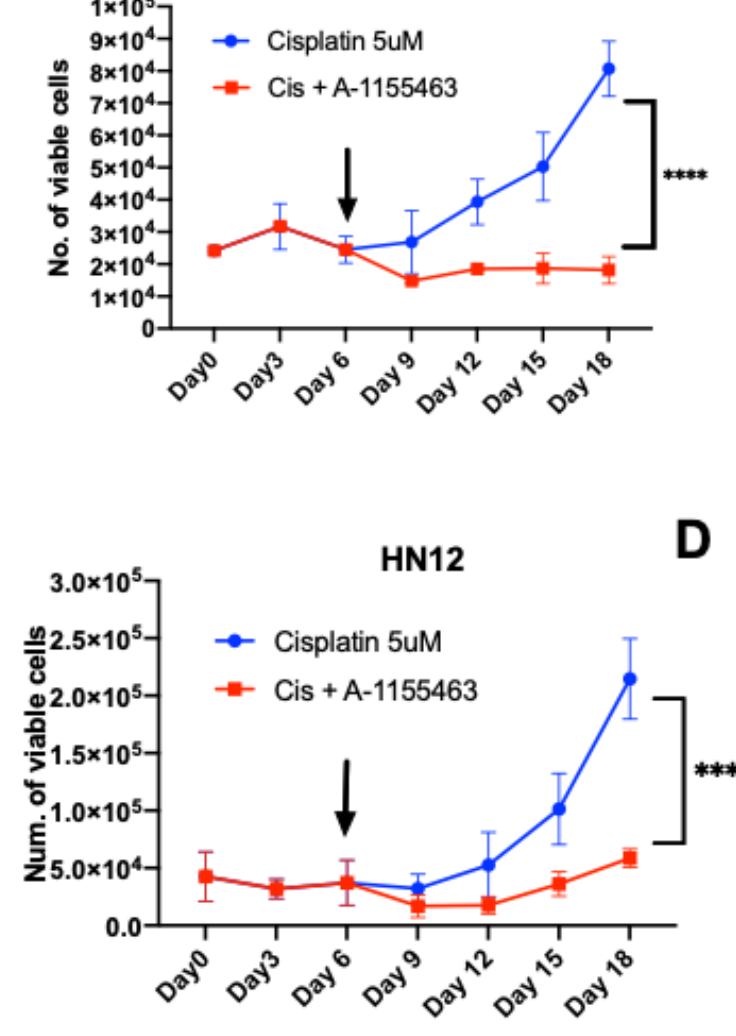

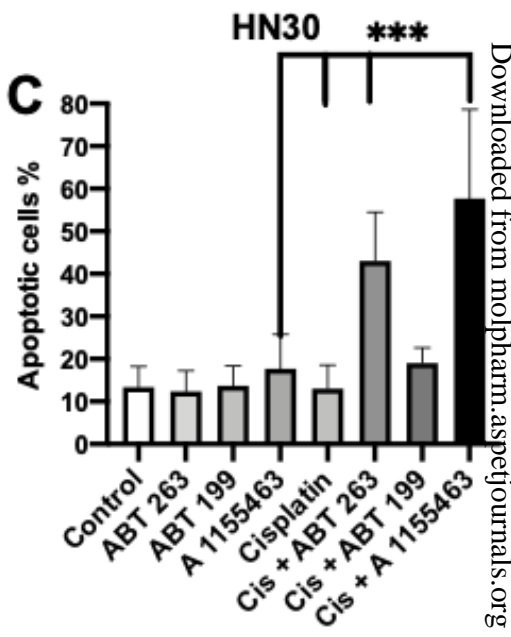

HN12

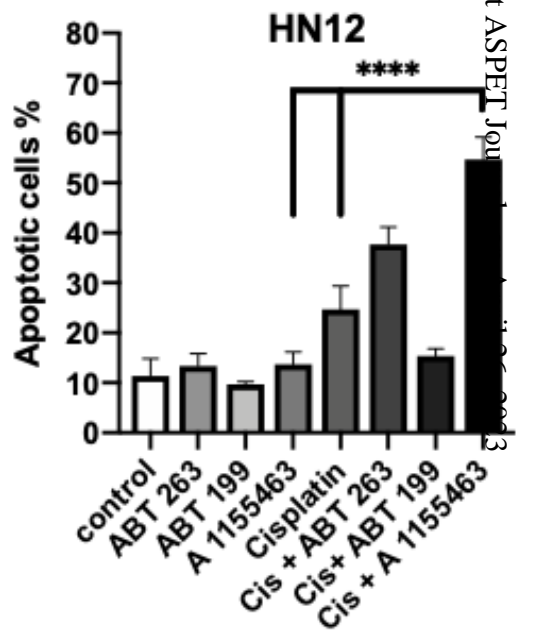




\section{Figure 5}

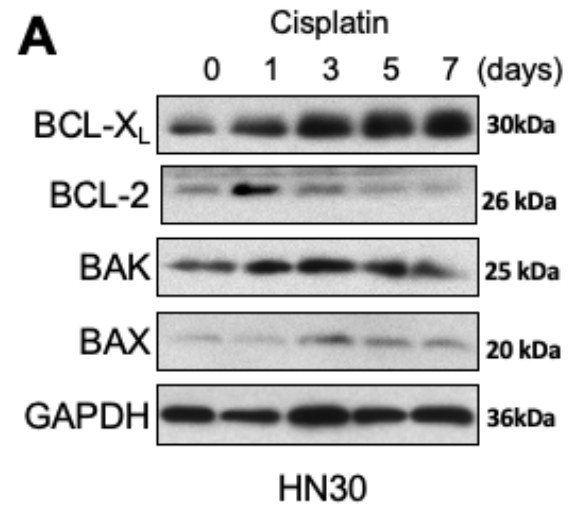

D

Crystal Violet

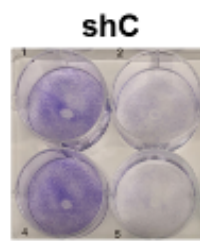

SA- $\beta$-gal
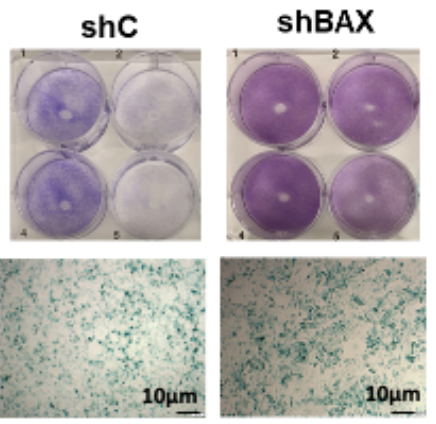

B

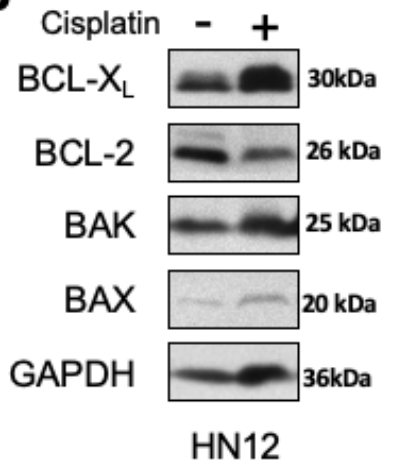

HN12
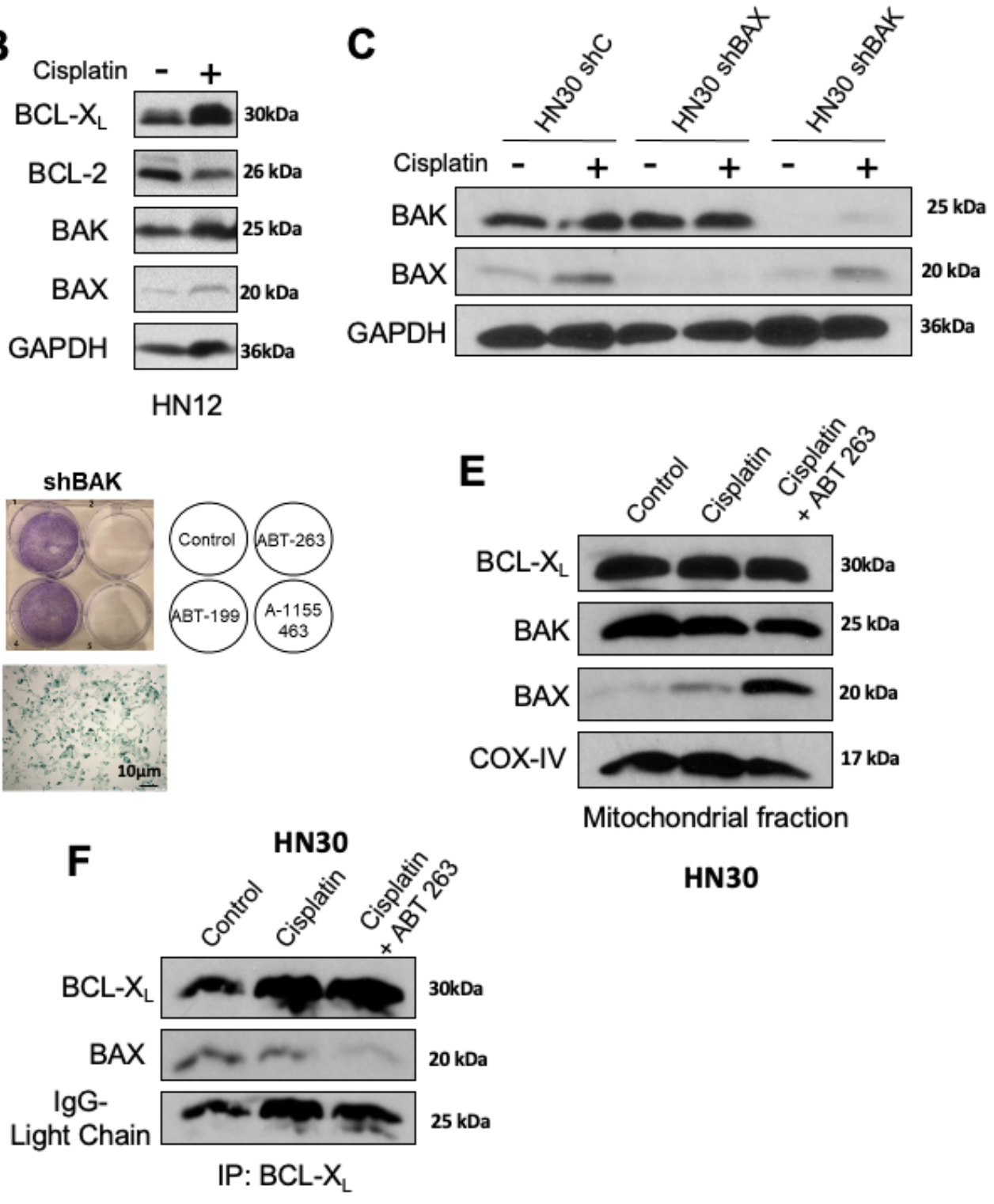

HN30 
Figure 6

A

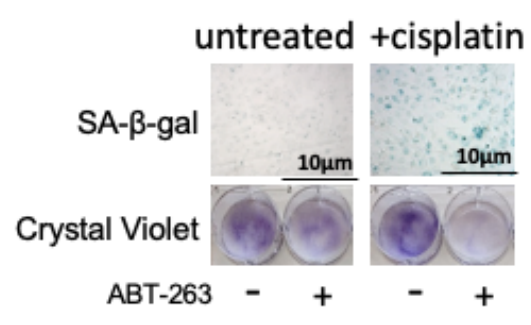

C

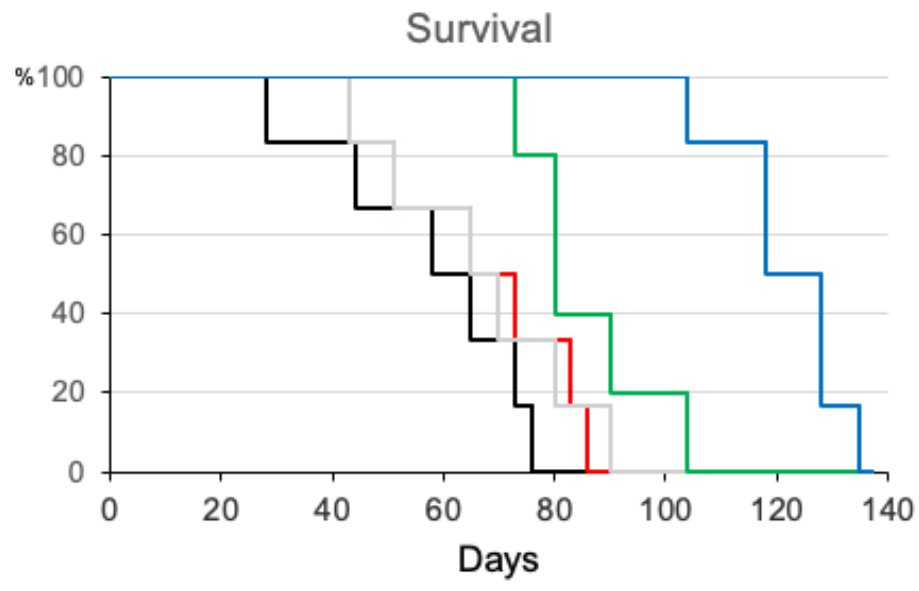

$-\mathrm{Ctrl}-\mathrm{ABT} 263-$ Cisplatin $-\mathrm{Cis}+\mathrm{ABT}-(\mathrm{Cis}+\mathrm{ABT}) \times 2$

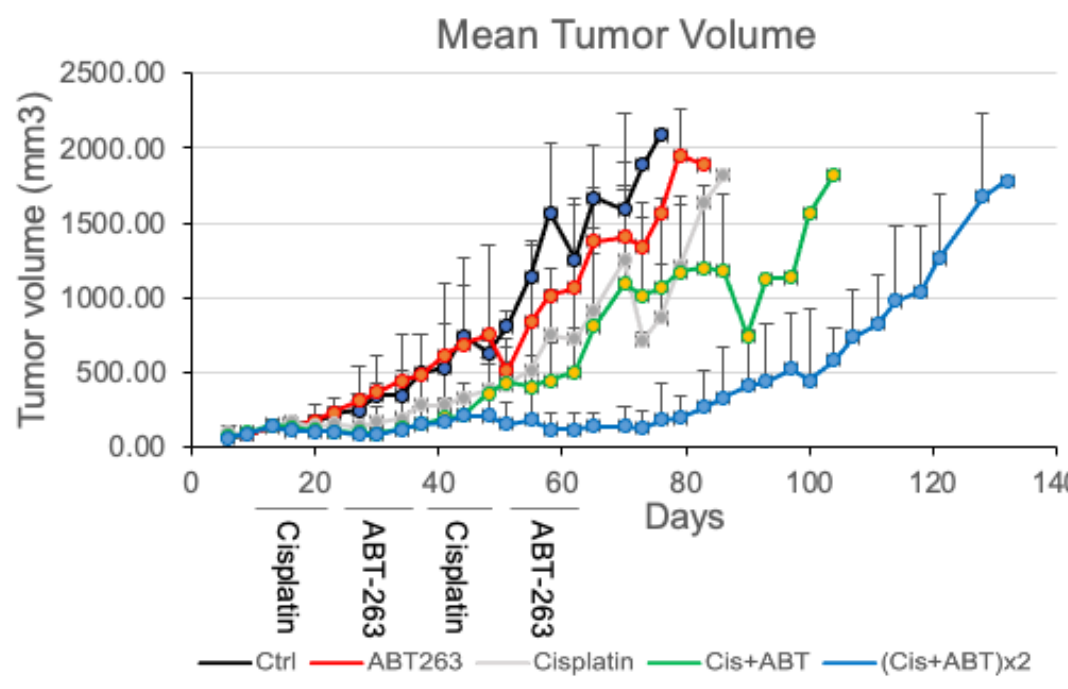

D

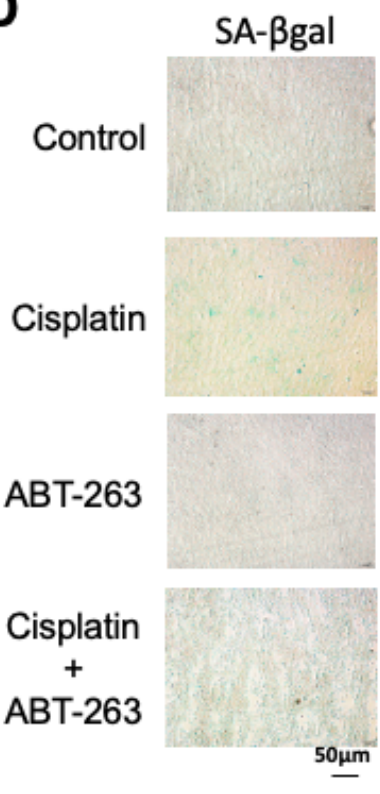

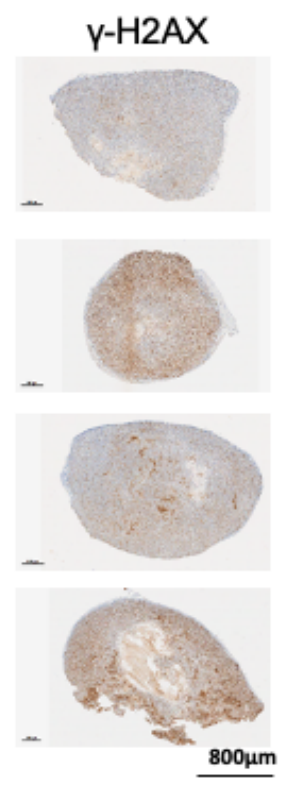

Cleaved Caspase 3

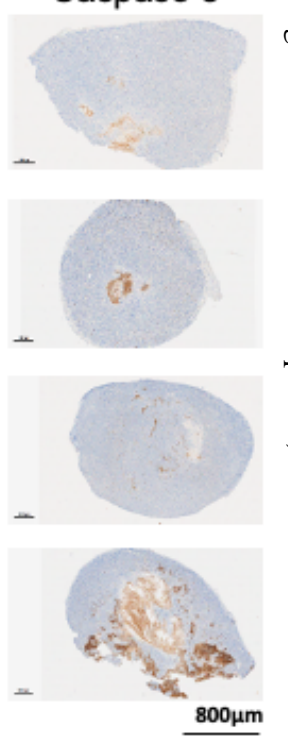




\section{Figure 7}

A

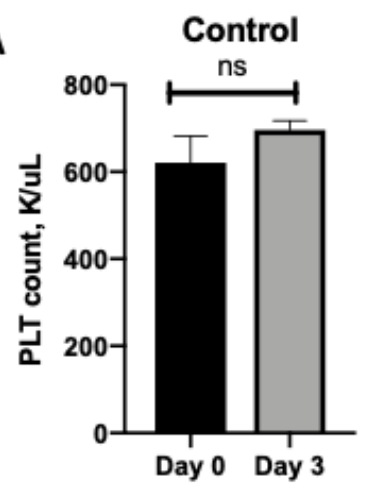

D

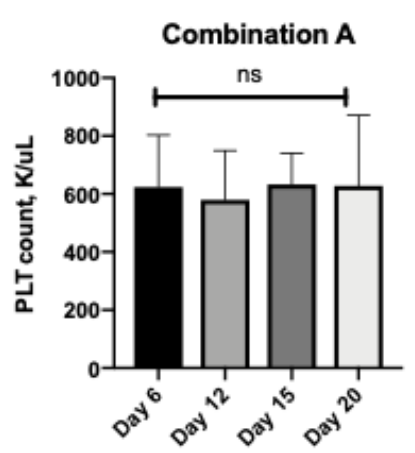

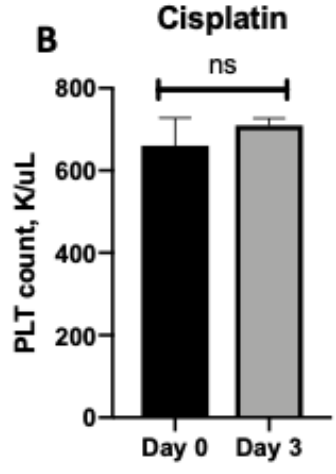

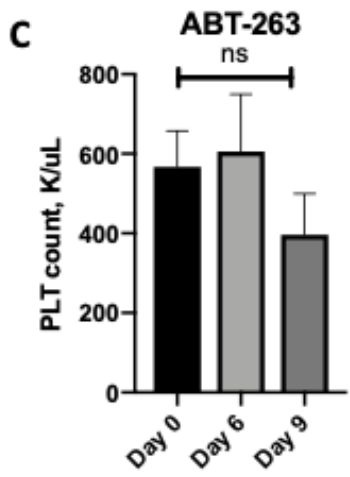

$\mathbf{E}$

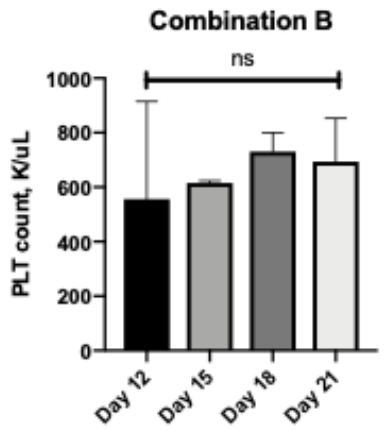

